\title{
Cognitive Decline, Cerebral-Spleen Tryptophan Metabolism, 0xidative Stress, Cytokine Production, and Regulation of the Txnip Gene in a Triple Transgenic Mouse Model of Alzheimer Disease
}

Emre Fertan, ${ }^{*}$ Gloria J. Rodrigues, ${ }^{*}$ Ryan V. Wheeler, ${ }^{*}$ Donna Goguen, ${ }^{*}$ Aimee A. Wong, ${ }^{*}$ Hana James, ${ }^{\dagger \ddagger}$ Andrew Stadnyk ${ }^{\dagger \dagger \delta}$ Richard E. Brown, ${ }^{*}$ and Ian C.G. Weaver ${ }^{\star \delta} \Phi \|$

From the Departments of Psychology and Neuroscience, ${ }^{*}$ Microbiology and Immunology, ${ }^{\dagger}$ Pediatrics, ${ }^{\ddagger}$ Psychiatry, ${ }^{\S}$ and Pathology ${ }^{\llbracket}$ and the Brain Repair Centre, Dalhousie University, Halifax, Nova Scotia, Canada

Accepted for publication

March 7, 2019.

Address correspondence to Ian C.G. Weaver, Ph.D., Department of Psychology and Neuroscience, Dalhousie University, Life Sciences Centre (Psychology Wing), 1355 Oxford St., Third Floor, Room 3340, Halifax, NS, Canada B3H 4R2. E-mail: ian.weaver@ dal.ca.

\begin{abstract}
Pathologic inflammation in response to injury, infection, or oxidative stress is a proposed mechanism relating cognitive decline to dementia. The kynurenine pathway and thioredoxin-interacting protein (TXNIP) activity regulate inflammation and neurotoxicity in Alzheimer disease (AD). We examined cognitive deficits, kynurenine pathway mediators, TXNIP, and oxidative damage in the cerebrum and spleen, including inflammatory cytokine production by stimulated splenocytes, from female triple transgenic (3xTg-AD) mice in early and late stages of disease progression, and characterized tissue-specific epigenetic regulation of Txnip gene expression. We show that cognitive deficits in 7-month-old 3xTg-AD mice are associated with a stable increase in cerebrum and spleen tryptophan metabolites, with a concomitant increase in amyloid $\beta 40$ $\left(A \beta_{40}\right) / A \beta_{42}$ and tau/hyperphosphorylated tau pathologies and a coordinated reduction in spleen proinflammatory cytokine production in 17-month-old mice. The enhanced cerebrum TXNIP expression is associated with increased histone acetylation, transcription factor [A $\beta_{42}$ or CCCTC-binding factor (CTCF)] binding, and Txnip promoter hypomethylation, whereas the attenuated spleen TXNIP expression is associated with increased histone methylation, reduced CTCF binding, and Txnip promoter hypermethylation. These results suggest a causal relationship among epigenomic state, TXNIP expression, cerebral-spleen tryptophan metabolism, inflammatory cytokine production, and cognitive decline; and they provide a potential mechanism for Txnip gene regulation in normal and pathologic conditions, suggesting TXNIP levels may be a useful predictive or diagnostic biomarker for $A \beta_{40} / A \beta_{42}$ targeted $A D$ therapies. (Am J Pathol 2019, 189: 1435-1450; https://doi.org/10.1016/j.ajpath.2019.03.006)
\end{abstract}

\begin{abstract}
Alzheimer disease (AD) is the most common cause of dementia, ${ }^{1}$ characterized neuropathologically by the accumulation of amyloid beta $(\mathrm{A} \beta)$ and intracellular neurofibrillary tangles composed of hyperphosphorylated tau (p-tau) protein. ${ }^{2,3}$ The increase in microglial activation, oxidative stress, and inflammatory responses against the aggregates ${ }^{4}$ promote neuronal damage and cell death. ${ }^{5}$ The release of locally acting proinflammatory cytokines from damaged neurons and surrounding glia stimulate the posterior hypothalamus to increase systemic sympathetic output, including catecholamine release from the adrenal medulla into the bloodstream. ${ }^{6}$
\end{abstract}

In relation to its role in immune responses, ${ }^{7}$ the spleen is an important target for studying the peripheral markers of AD. Activation of adrenergic and cholinergic receptors, expressed on splenic macrophages, regulates the secretion of proinflammatory cytokines into the peripheral circulation, which pass the blood-brain barrier and enhance the immunologic response. ${ }^{8}$ The increase of proinflammatory

\footnotetext{
Supported by Natural Sciences and Engineering Research Council of Canada discovery grants RGPIN-2013-436204 (I.C.G.W), RG7441 (R.E.B), and RGPIN-2015-04923 (A.S.).

Disclosures: None declared.
} 
cytokines in peripheral tissues in response to $A \beta$ aggregates in the central nervous system (CNS) provides a potentially useful early diagnostic marker for $\mathrm{AD}$ detection. ${ }^{9,10} \mathrm{In} \mathrm{AD}$, the internalization of $A \beta_{42}$ appears to be facilitated by the high-affinity binding of $A \beta_{42}$ to the $\alpha-7$ nicotinic acetylcholine receptor. ${ }^{11}$ Consistent with this, stimulation of the spleen $\alpha-7$ nicotinic acetylcholine receptor by the vagus nerve inhibits the release of proinflammatory cytokines, ${ }^{12}$ suggesting a common mechanism in the CNS and spleen for pathologic inflammation and selective vulnerability of neurons.

Chronic inflammatory responses in the CNS promote neuronal death through activation of the kynurenine (KP) and thioredoxin (TRX) reduction pathways. ${ }^{13-15} \mathrm{~A} \beta_{42}$ and interferon-gamma (IFN- $\gamma$ ) increase indoleamine 2,3dioxygenase (IDO) expression, which is the first and ratelimiting enzyme of the KP. ${ }^{16}$ Increased KP activity depletes tryptophan ${ }^{17}$ and augments levels of 3hydroxykynurenine, ${ }^{18}$ oxidative stress, and apoptosis. ${ }^{19}$ Young and adult AD model (3xTg-AD) mice have increased forebrain levels of the N-methyl-D-aspartate receptor agonist quinolinic acid (QA), ${ }^{20}$ which is associated with increases in excitotoxicity ${ }^{21}$ and p-tau accumulation. ${ }^{22}$

TRX and thioredoxin-interacting protein (TXNIP) interactions help maintain the cellular oxidation/reduction balance. ${ }^{23}$ TRX promotes a decrease in oxidative stress by reducing reactive oxygen species, such as nitric oxide and hydrogen peroxide, whereas TXNIP inhibits this process. ${ }^{24}$ $\mathrm{AD}$ pathology is associated with an age-related decrease in TRX expression and an increase in TXNIP, reactive oxygen species, and oxidative damage. ${ }^{25,26}$ Consistent with this, 11month-old AD model (B6.Cg-Tg) mice have increased urine levels of 8-hydroxy-2'-deoxyguanosine $(8-\mathrm{OHdG}),{ }^{27}$ which is a biomarker for oxidative stress. ${ }^{28}$ The calcium channel inhibitor Verapamil suppresses TXNIP expression, TXNIP-mediated p38 mitogen-activated protein kinase phosphorylation, and p-tau accumulation in mice with $\mathrm{AD}$ like disease. ${ }^{29}$ Similarly, the antioxidant Dl-3-n-butylphthalide suppresses TXNIP expression and reduces levels of programmed cell death (apoptosis) in mice with AD-like disease and human-derived neuronal cells as AD model systems. ${ }^{30}$ These findings suggest that identification and targeting of endogenous upstream mediators that prevent oxidative damage or inhibit inflammation in the brain and spleen may help lead to improved therapeutic strategies against $\mathrm{AD}$ progression.

Although cognitive decline, tryptophan metabolism, and inflammatory cytokine production have been investigated in the brains of older symptomatic mouse models of $\mathrm{AD}$, it is unclear whether tryptophan metabolism and TXNIP expression are differently affected in symptomatic younger mice versus the older AD-like mice. Moreover, it remains unclear whether changes in tryptophan metabolism and TXNIP expression are limited to the CNS. We, therefore, evaluated the levels of $\mathrm{A} \beta_{40}, \mathrm{~A} \beta_{42}, \mathrm{IFN}-\gamma$, IDO, QA, TXNIP, 8-OHdG, tau, and p-tau proteins in cerebrum and spleen from 7- and 17-month-old female triple transgenic $\mathrm{AD}$ model $(3 \mathrm{xTg}-\mathrm{AD})$ mice and compared them with ageand sex-matched 129C57BL/6 wild-type (WT) mice. The 3xTg-AD mice express three transgenes-amyloid precursor protein (APP), presenilin-1, and tau-that phenocopy the critical aspects of $\mathrm{AD}$ neuropathology, ${ }^{31}$ providing a useful model to study the role of $A \beta$ accumulation on the temporal expression patterns of TXNIP and key mediators of tryptophan metabolism and their relation to p-tau accumulation.

\section{Materials and Methods}

\section{Animals and Behavioral Testing}

The $3 \times \mathrm{xTg}-\mathrm{AD}$ mice were engineered by injecting $A P P_{S w e}$ and $\operatorname{tau}_{P 301 L}$ to single-cell embryos of homozygous $P S 1_{M 146 V}$ knock-in mice, causing $\mathrm{A} \beta_{42}$ aggregation in the frontal cortex and the hippocampus, starting at 3 months of age; extracellular plaques in the frontal cortex and the hippocampus at 6 months of age; and tau tangles at 12 months of age. ${ }^{31}$ Our laboratory has previously shown working memory deficits in the $3 \mathrm{xTg}$-AD mice starting at 2 months of age, ${ }^{32}$ as well as spatial memory deficits and improved motor performance at 6 months of age. ${ }^{33,34} \mathrm{~A}$ total of nine female 3xTg-AD (five at 7 months, four at 17 months) and nine female B6129SF2/J wild-type control mice (five at 7 months, four at 17 months) were used in this study. All of the mice were born in-house from breeding pairs originally purchased from Jackson Laboratories (Bar Harbor, ME; JAX stock 34830). Mice were housed in same-sex groups of two to four in translucent polyethylene cages $(13 \times 30 \times 15$ $\mathrm{cm}$ ) with wire food hoppers and microisolator filter lids, in a climate-controlled $\left(20^{\circ} \mathrm{C} \pm 2^{\circ} \mathrm{C}\right)$ vivarium on a reversed 12:12-hour light/dark cycle with lights off at $10 \mathrm{AM}$. The mice were fed Purina Laboratory Rodent Chow number 5001 (Agribrand Purina, Strathroy, ON, Canada) and tap water, ad libitum. A black polyethylene tube $(4-\mathrm{cm}$ diameter, $7.5-\mathrm{cm}$ length) was placed in the cages for environmental enrichment. Mice were transported to clean cages once a week.

The Barnes maze is a white polyethylene platform (122$\mathrm{cm}$ diameter) elevated $48.4 \mathrm{~cm}$ from the floor with 16 holes (4.45-cm diameter) equally spaced around the perimeter 1.3 $\mathrm{cm}$ from the edge, as described by O'Leary and Brown. ${ }^{35}$ Four of the holes $(4,8,12$, and 16) were capable of having a black plastic escape box beneath them. A buzzer (0 to $37.2 \mathrm{kHz}, 89 \mathrm{~dB}$ ) and two $150-\mathrm{W}$ flood lamps placed 155 $\mathrm{cm}$ above the maze were used as aversive stimuli. A polyvinyl-chloride tube ( $8-\mathrm{cm}$ diameter, $12.5-\mathrm{cm}$ height) was used to hold the mouse in the center of the maze before the trial began. A camera was mounted $1.7 \mathrm{~m}$ above the maze, and the Limelight tracking system (Actimetrics, Wilmette, IL) was used to track the location of the mice. Mice were habituated to the maze by placing them under a 5 -L beaker closed on top of the correct escape hole for 5 
minutes on day 1. Acquisition training starts on day 2 and goes for 15 days, during which the latency of the mice to find the escape hole as well as head dips to the holes are measured and compared for the genotypes. After acquisition, a 1-day probe trial is run to measure memory. Then, mice are trained for the reversal acquisition, in which the escape hole is in the opposite location of the original. All procedures were performed according to guidelines developed by the Canadian Council on Animal Care, and the protocol was approved by the Dalhousie University (Halifax, NS, Canada) Animal Care Committee (protocol approval number 16-017).

\section{Tissue Collection}

One week after the behavioral assessment, the 7-month-old mice were sacrificed. A second cohort of mice was sacrificed at 17 months of age. In both cases, a cardiac puncture was performed under anesthesia (isoflurane; $1 \%$ to $5 \%$ in oxygen), after checking the toe-pinch reflex for signs of pain perception. Mice were then perfused with $10 \%$ phosphatebuffered saline solution for 2 minutes, the carcasses were decapitated, and brains were harvested. Tissues were collected in $1.5-\mathrm{mL}$ microcentrifuge tubes, frozen with dry ice, and stored at $-80^{\circ} \mathrm{C}$.

\section{Protein Isolation and Antibody Enzyme-Linked Immunosorbent Assay}

Frozen cerebrum and spleen tissue was weighted, mechanically homogenized in ice-cold Tris-buffered saline supplemented with protease inhibitors (P8340; Sigma, St. Louis, $\mathrm{MO}$ ) and $2 \mathrm{mmol} / \mathrm{L}$ EDTA, and ultracentrifuged $\left(100,000 \times g, 20\right.$ minutes, $\left.4^{\circ} \mathrm{C}\right)$. The resultant Triton X-100 (Sigma, St. Louis, MO) insoluble pellet was then dissolved to half of the initial homogenization volume in $70 \%$ formic acid and centrifuged $\left(14,000 \times g, 10\right.$ minutes, $\left.4^{\circ} \mathrm{C}\right)$. The supernatant was evaporated off to $70 \%$ of the volume with a nitrogen stream and neutralized to $\mathrm{pH} 7$ with $5 \mathrm{~mol} / \mathrm{L} \mathrm{NaOH}$ in $1 \mathrm{~mol} / \mathrm{L}$ Tris. Enzyme-linked immunosorbent assays were used to detect $A \beta_{40}$ and $A \beta_{42}$ [detection range (DR), 7.4 to $250 \mathrm{pg} / \mathrm{mL}$; BioLegend, San Diego, CA; catalog numbers 841301 and 842401, respectively], IFN- $\gamma$ (DR, 15.6 to 1000 $\mathrm{pg} / \mathrm{mL}$; Cloud-Clone Corp., Katy, TX; catalog number SEA049Mu), IDO (DR, 3.12 to $200 \mathrm{ng} / \mathrm{mL}$; Cloud-Clone Corp.; catalog number SEB547Mu), QA (DR, 1.23 to 100 ng/mL; Aviva Systems Biology, San Diego, CA; catalog number OKCD02284), TXNIP (DR, 28 to $1800 \mathrm{pg} / \mathrm{mL}$; Cusabio Technology LLC, Houston, TX; catalog number CSB-EL025383MO), 8-OHdG (DR, 0.94 to $60 \mathrm{ng} / \mathrm{mL}$; StressMarq Biosciences Inc., Victoria, BC, Canada; catalog number SKT-120-96S), tau, and p-tau (phosphorylated Ser396) (minimum detection threshold of 5000 targetexpressing HeLa cells; Aviva Systems Biology; catalog number OKAG02074). From pilot results for each assay, 10 to $40 \mu \mathrm{g}$ of each sample was loaded in triplicate alongside an eight-point standard curve in duplicate (with controls) in the 96-well microtiter plates supplied by each manufacturer. Detection was performed with horseradish peroxidase-labeled, $\mathrm{Fc}$-specific $\mathrm{IgG}$ and read in the microplate reader at a wavelength of $620 \mathrm{~nm}\left(\mathrm{~A} \beta_{40}\right.$ and $\left.\mathrm{A} \beta_{42}\right), 540 \mathrm{~nm}(\mathrm{QA}, \mathrm{IFN}-\gamma$, and TXNIP), or $450 \mathrm{~nm}$ (IDO, 8 -OHdG, tau, and p-tau). The blank corrected levels of each target protein are reported in $\mathrm{pg} / \mathrm{mL}$.

\section{Spleen Cell Isolation, Flow Cytometric Analysis, and Cytokine Detection}

Spleens were isolated from 17-month-old mice, and singlecell suspensions were prepared by passing the tissue through a 100- $\mu \mathrm{m}$ nylon mesh screen. Spleen cells were washed using RPMI 1640 medium, and red cells were lysed using $1 \times$ red cell lysis buffer (eBiosciences, San Diego, CA). The cells were washed twice, counted, and resuspended in stimulation medium containing 10\% fetal bovine serum. All antibodies were purchased from BD Biosciences (San Jose, CA) or eBiosciences, Inc. (San Diego, CA). Two-color (phosphatidylethanolamine and allophycocyanin) fluorescent flow cytometric analyses were performed to determine the spleen cell phenotypes. Cells were washed with staining medium and stained with a combination of the following rat monoclonal antibodies: CD4 (Ly-4) and CD8 (Ly-2) for 10 minutes at $4{ }^{\circ} \mathrm{C}$. After incubation with monoclonal antibody, cell signals were acquired with an FACSCalibur analyzer (BD Biosciences). Forward and side scatter parameters were chosen to identify lymphocytes, and positive stain was determined using fluorescent-conjugated isotype control antibodies. Data were analyzed using Flow Cytometry Software (FCS) Express 6 version 6.06 (De Novo Software, Los Angeles, CA). Furthermore, single-cell suspensions of spleens were cultured (48 hours) in the presence of antiCD3 plus anti-CD28 coated beads (Dynabeads; Gibco, Dún Laoghaire, Ireland). Culture supernatants were assessed in three separate experiments for tumor necrosis factor and IFN- $\gamma$ cytokine levels using an enzyme-linked immunosorbent assay (BioLegend; catalog numbers 430901 and 430801, respectively), following the manufacturer's instructions.

\section{Western Blot Analysis}

Tissue samples were dissolved in $200 \mu \mathrm{L}$ lysis buffer containing $7.5 \mathrm{mmol} / \mathrm{L}$ HEPES (pH 7), $1.5 \mathrm{mmol} / \mathrm{L}$ EDTA, 1.5 $\mathrm{mmol} / \mathrm{L}$ EGTA, $0.375 \mathrm{mmol} / \mathrm{L}$ dithiothreitol, protease inhibitor cocktail (P8340; Sigma), phosphatase inhibitor cocktail (P5726; Sigma), and 25\% of 10\% SDS (Amresco Pure, Solon, OH; technology grade); concentrations were determined using the bicinchoninic acid protein assay kit (Pierce Biotechnology, Rockford, IL) on a standard plate reader. Equal amounts of protein were separated on a $4 \%$ to $20 \%$ Bis-Tris gel (Bio-Rad, Mississauga, ON, Canada) and transferred to nitrocellulose membranes. Membranes were 
blocked overnight in $5 \%(\mathrm{w} / \mathrm{v})$ bovine serum albumin in $0.1 \%$ Tween $20-$ Tris-buffered saline. After blocking, the membranes were incubated ( 1 hour, $20^{\circ} \mathrm{C}$ to $21^{\circ} \mathrm{C}$ ) with primary antibodies toward TXNIP (dilution 1:500; Cell Signaling Technology, Danvers, MA; catalog number D5F3E), CTCF (dilution 1:200; catalog number 07-729; MilliporeSigma, Burlington, MA), or $\beta$-actin (dilution 1:1000; Abcam, Cambridge, MA; catalog number ab8226). The membranes were then washed in Tween 20-Trisbuffered saline ( 20 minutes, $20^{\circ} \mathrm{C}$ to $21^{\circ} \mathrm{C}$ ) and incubated ( 1 hour, $20^{\circ} \mathrm{C}$ to $21^{\circ} \mathrm{C}$ ) with specific horseradish peroxidase-conjugated secondary antibodies at a dilution of 1:10,000 (Jackson ImmunoResearch Laboratories, West Grove, PA). The immunoblot bands were developed using enhanced chemiluminescent substrate (Pierce), imaged using the ChemiDoc Touch Imaging System (Bio-Rad), and captured with a ChemiDoc Touch Imaging System (Bio-Rad). The intensity of each band was quantified with Image Lab software version 6.0.1 (Bio-Rad). $\beta$-Actin levels were used to verify uniform loading of each sample.

\section{Quantitative PCR}

Total RNA was isolated from brain and spleen using the RNeasy minikit protocol (Qiagen, Valencia, CA) and quantified with a Take3 Micro-volume Plate on an Epoch Spectrophotometer (BioTek Instruments Inc., Winooski, VT). RNA integrity was confirmed using an Experion Automated Electrophoresis System and RNA StdSens chip (Bio-Rad). The RNA quality index value for all samples was $>7.9$, with low degradation. RNA $(2 \mu \mathrm{g})$ was converted into cDNA using the iScript cDNA Synthesis Kit (Bio-Rad). RT-PCR was performed using SsoFast EvaGreen Supermix (Bio-Rad) and gene-specific primers for Txnip (forward, 5' CTGGCGTAAGCTTTTCAAGG-3'; reverse, 5'-AGTGCACAAAGGGGAAACAC- $3^{\prime}$ ) and $r p l 13 a$ (forward, $5^{\prime}$-ACAAGAAAAAGCGGATGGTG-3'; reverse, 5'-TTCCGGTAATGGATCTTTGC- $3^{\prime}$ ). Reactions were conducted on the CFX96 Touch Real-Time Detection System (Bio-Rad), standard curves for each primer set were generated, and primer efficiencies were incorporated into the CFX Maestro Software version 1.1 (Bio-Rad). Relative Txnip mRNA expression was calculated using the $2_{\mathrm{T}}^{-\Delta \Delta \mathrm{C}}$ method of Livak and Schmittgen ${ }^{36}$ and normalized to rpl13a as a reference gene.

\section{ChIP Assays}

Chromatin immunoprecipitation (ChIP) assays were performed as previously described. ${ }^{37}$ Tissues were fixed with $1 \%$ formaldehyde, and the resulting cross-linked protein-DNA complexes were sonicated, using a Q800R2 sonicator (QSonica, Newtown, CT), into 150- to 250bp-length fragments, confirmed using a QIAxcel Advanced System Bioanalyzer (Qiagen N.V., Venlo, the Netherlands). Immunoprecipitation was then performed using rabbit polyclonal $\mathrm{IgG}$ antibodies against 5-methylcytosine (5mC) (catalog number BI-MECY-0500; AnaSpec, Inc., Fremont, $\mathrm{CA}$ ), $\mathrm{A} \beta_{42}$ (catalog number AB5078P; MilliporeSigma), CTCF (catalog number 07-729; MilliporeSigma), as well as the control normal rabbit IgG (catalog number sc-2027; Santa Cruz Biotechnology, Dallas, TX). After immunoprecipitation, the precipitated DNAprotein complexes were dissociated from the protein A conjugated Dynabeads (Invitrogen, Carlsbad, CA) and isolated using a Purelink PCR purification kit (Invitrogen), along with their respective total input controls (preimmunoprecipitation DNA). Real-time quantitative PCR analysis was then performed using primers targeting the $A \beta$ interacting domain (A $\beta I D)$ and $\mathrm{CTCF}$ response element (RE) sites spanning the Txnip gene promoter $(A \beta I D$ RE region: forward, 5'-CAACCCAGTTAGGGCGC-3'; reverse, 5'-CCACCCACCCACTCCC-3') and 5'-untranslated region (CTCF RE region: forward, 5'-GGAGCACACCGTGTCCA-3'; reverse, $3^{\prime}$ AATAACAGCTGTCTTCCGC-3'), with equipment and reagents described above. Results are expressed as the fold change of the enrichment of the DNA detected under the treatment conditions against the DNA detected under the no treatment conditions. This was determined by dividing the signals obtained from the ChIP by the signals obtained from the total input control sample and normalizing for the DNA detected by the nonimmune IgG (negative control). For sequential ChIP (ChIP-re-ChIP) experiments, the protein bound to the beads with the first antibody was incubated (30 minutes, $37^{\circ} \mathrm{C}$ ) twice with $20 \mathrm{mmol} / \mathrm{L}$ dithiothreitol, and the combined elutes were suspended in ChIP dilution buffer, which was then immunoprecipitated $\left(14\right.$ hours, $\left.4^{\circ} \mathrm{C}\right)$ with the second antibody.

\section{Bisulfite Conversion and Pyrosequencing}

As previously described, ${ }^{38}$ DNA methylation was analyzed by sodium bisulfite pyrosequencing on a PyroMark Q24 Advanced pyrosequencer using the DNA EpiTect Fast DNA Bisulfite Kit and PyroMark PCR Kit (Qiagen N.V., Venlo, the Netherlands), according to the manufacturer's instructions, beginning with $500 \mathrm{ng}$ template DNA. Two custom assays covering the $A \beta I D$ and CTCF $R E$ sites spanning the Txnip gene promoter and $5^{\prime}$-untranslated region, respectively, were designed using PyroMark Assay Design software version 2.0 (Qiagen N.V.) and validated to amplify a single PCR product $(A \beta I D=278 \mathrm{nt}$, CTCF $\mathrm{RE}=319 \mathrm{nt}$ ). Primers for the $A \beta I D \mathrm{RE}$ assay were as follows: forward, 5'-TGTTAGTTTTAGGGTGTTAATTTAGTTAG-3'; reverse, 5'-CCCCCTACTCTATTCCCC(biotin)- $3^{\prime} ; \quad$ and sequencing, $5^{\prime}$ GGGTGTTAATTTAGTTAGG-3' ${ }^{\prime}$. Primers for the CTCF RE assay were as follows: forward, $5^{\prime}$-(biotin) GTTTTTTTTGTTGGTAAGGTTG-3'; reverse, 5'-ACTATACCAAAAACTTTCAAAAA- $3^{\prime}$; and sequencing, $5^{\prime}$ ATCTTCCCCAACTAAAAAAACTCTA-3'. PCR 
conditions for both assays were as follows: $95^{\circ} \mathrm{C}, 15 \mathrm{mi}-$ nutes $\left(94^{\circ} \mathrm{C}, 30\right.$ seconds; $56^{\circ} \mathrm{C}, 30$ seconds; $72^{\circ} \mathrm{C}, 30$ seconds) $\times 50$ cycles; and $72^{\circ} \mathrm{C}, 10$ minutes.

\section{Experimental Design and Statistical Analysis}

Animals were earmarked and given a unique number. During experiments and analysis, the investigators (E.F., G.J.R., R.V.W., D.G, A.A.W., H.J., I.C.G.W.) were blinded to the animal's age and genotype. For the Barnes maze, previous data from our laboratory demonstrated the need for a minimum of seven animals per group to detect a significant difference at $95 \%$ confidence $(\beta=0.05) .{ }^{34,35}$ Analysis of variance with genotype (WT or 3xTg-AD) and age (7 or 17 months) were used to compare the groups. Interactions were analyzed post hoc with simple effects analyses. For the spleen and epigenetic analyses, Welch $t$-tests were performed. Results were considered significant if $P<0.05$. The $\mathrm{R}$ stats version 3.5.0 Joy in Playing (https://www.rproject.org; $\mathrm{R}$ Foundation for Statistical Computing, Vienna, Austria) was used for all of the analyses.

\section{Results}

Early Neuropathology Is Predicted by Spatial Learning Deficits in $3 x T g-A D$ Mice

At 7 months of age, $A \beta$ pathology and synaptic dysfunction are apparent-with diffuse amyloid plaques in the neocortex and intraneuronal $A \beta$ accumulation in pyramidal neurons of the hippocampus, cortex, and amygdala of the $3 \mathrm{xTg}-\mathrm{AD}$ mice. ${ }^{31}$ Analysis of cognitive function at this time point is crucial to determine whether these mice also show learning and memory impairments. Barnes maze analysis revealed that 3xTg-AD and WT mice did not perform differently in the acquisition phase for spatial learning at 7 months of age (data not shown). However, in the reversal acquisition phase, $3 x T g-A D$ mice made significantly more errors than WT mice $[F(1,16)=5.83, P<0.05]$ (Figure $1 \mathrm{~A}$ ) and showed the least improvement over the 5-day training period $[F(4,64)=11.99, P<0.005]$ (Figure 1B). Although there was no significant effect of genotype on the latency to find the escape hole during the reversal phase $[F(1,16)=0.02, P>0.05]$ (Figure 1C), all of the mice showed a decrease in their latency to find the escape hole during the 5-day training period $[F(4,64)=7.22$, $P<0.005$ ] (Figure 1D).

$3 \times T g-A D-$ Associated Increases in CNS $A \beta$, IFN- $\gamma$, ID0, $\mathrm{QA}$, TXNIP, 8-OHdG, and ( $\mathrm{p}-$ ) Tau Persist with Aging

To examine how the emergence of cognitive impairments relates to the hallmark features of $\mathrm{AD}$ neuropathology, especially in the process of aging (Figure 2A), the protein levels of key mediators of the KP and TRX pathways $-\mathrm{A} \beta_{40}, \mathrm{~A} \beta_{42}$, IFN- $\gamma$, IDO, QA, TXNIP, 8-OHdG, tau, and p-tau-were measured in cerebrum from 7- and 17month-old female 3xTg-AD mice. These mice were compared with age- and sex-matched WT control mice. In both young and aged animals, the levels of $\mathrm{A} \beta_{40}$ in the cerebrum were significantly higher in the $3 \times \mathrm{Tg}-\mathrm{AD}$ mice than in the WT mice $[F(1,14)=56.17, P<0.001]$. Levels of $\mathrm{A} \beta_{40}$ were significantly higher in the cerebrum from aged mice compared with that of younger $3 \times \mathrm{Tg}-\mathrm{AD}$ mice $[F(1,14)=22.33, P<0.001]$, with a genotype $\times$ age interaction $[F(1,14)=18.17, P<0.001]$ (Figure 2B). In both young and aged animals, the level of $\mathrm{A} \beta_{42}$ in cerebrum from $3 \times \mathrm{Tg}$-AD mice was also significantly higher than that of WT mice $[F(1,14)=37.14, P<0.001]$. Levels of $\mathrm{A} \beta_{42}$ in the cerebrum significantly increased with age in the 3xTg-AD mice $[F(1,14)=20.45, P=0.001]$ (Figure 2C). For the $\mathrm{A} \beta_{42} / \mathrm{A} \beta_{4 \mathrm{o}}$ ratio, there was a main effect of genotype $[F(1,10)=24.25, P<0.001]$ and a genotype $\times$ age interaction $[F(1,10)=7.95, P=0.02]$. The $\mathrm{A} \beta_{42} / \mathrm{A} \beta_{4 \mathrm{o}}$ ratio was significantly higher in the cerebrum from aged $3 \times \mathrm{Tg}-\mathrm{AD}$ mice than it was in younger $3 \mathrm{xTg}-\mathrm{AD}$ mice. The $\mathrm{A} \beta_{42} / \mathrm{A} \beta_{4 \mathrm{o}}$ ratio in the cerebrum was significantly lower in aged WT mice by comparison to younger WT mice (Figure 2D). The level of IFN- $\gamma$ was significantly higher in cerebrum from aged 3xTg-AD mice than aged WT mice and significantly lower in cerebrum from younger $3 \times \mathrm{Tg}-\mathrm{AD}$ mice by comparison to the WT control mice $[F(1,11)=25.63, P<0.001]$. The level of IFN- $\gamma$ was
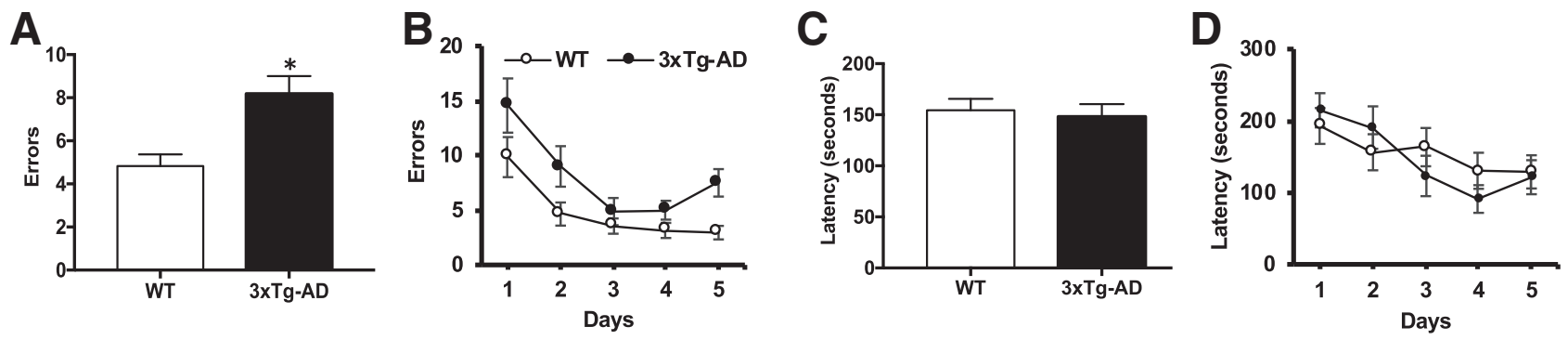

Figure 1 Spatial learning and memory performance of 7-month-old female 3xTg-AD and WT mice. $\mathbf{A}$ and $\mathbf{B}: 3 \times T g-A D$ mice made more errors in the reversal acquisition phase of the Barnes maze (A) and show less improvement over the 5-day period (B). C and D: $3 \times \mathrm{Tg}$-AD and WT mice do not differ in their latency to escape the Barnes maze. Data are expressed as means \pm SEM. ${ }^{*} P<0.05$ versus WT. 
A

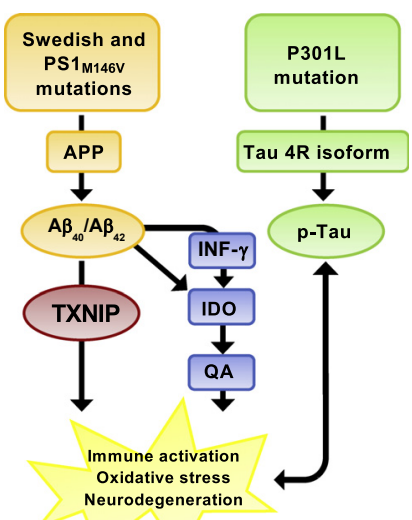

D

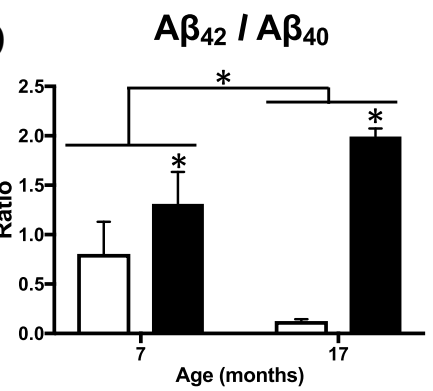

G

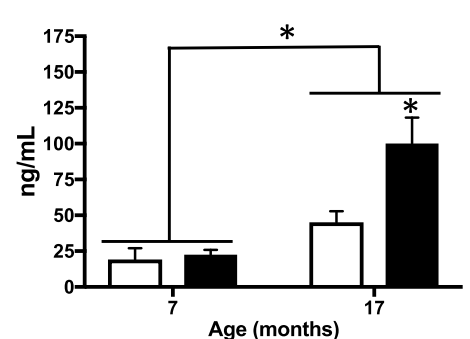

J

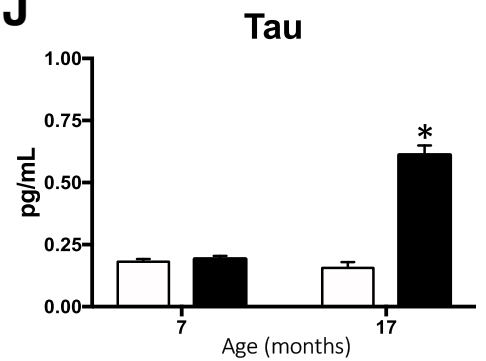

B

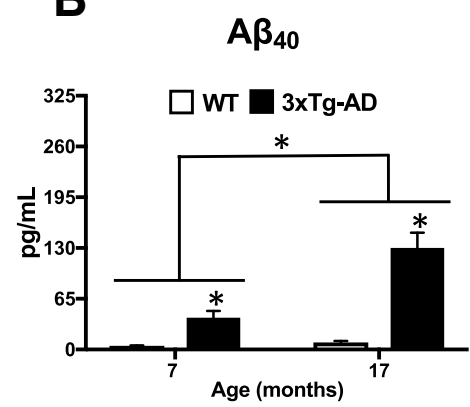

C
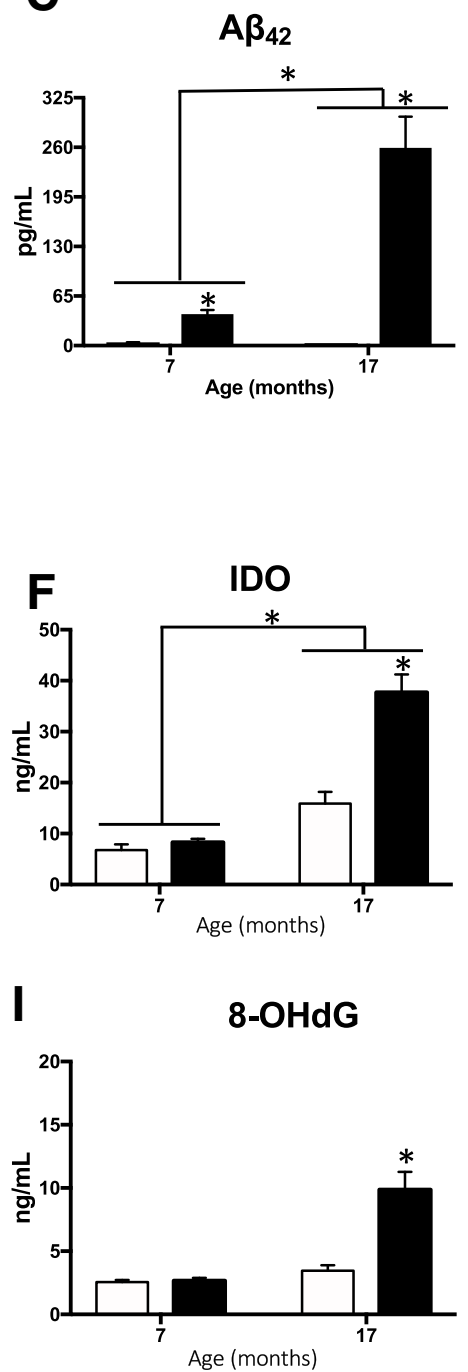

8-OHdG

L
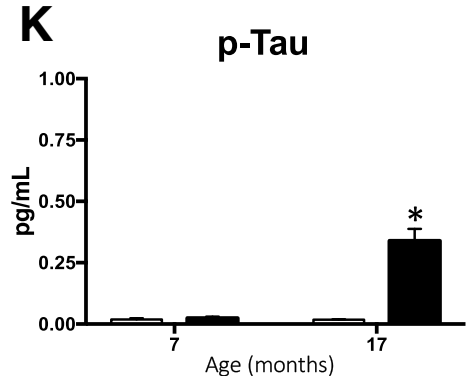

I
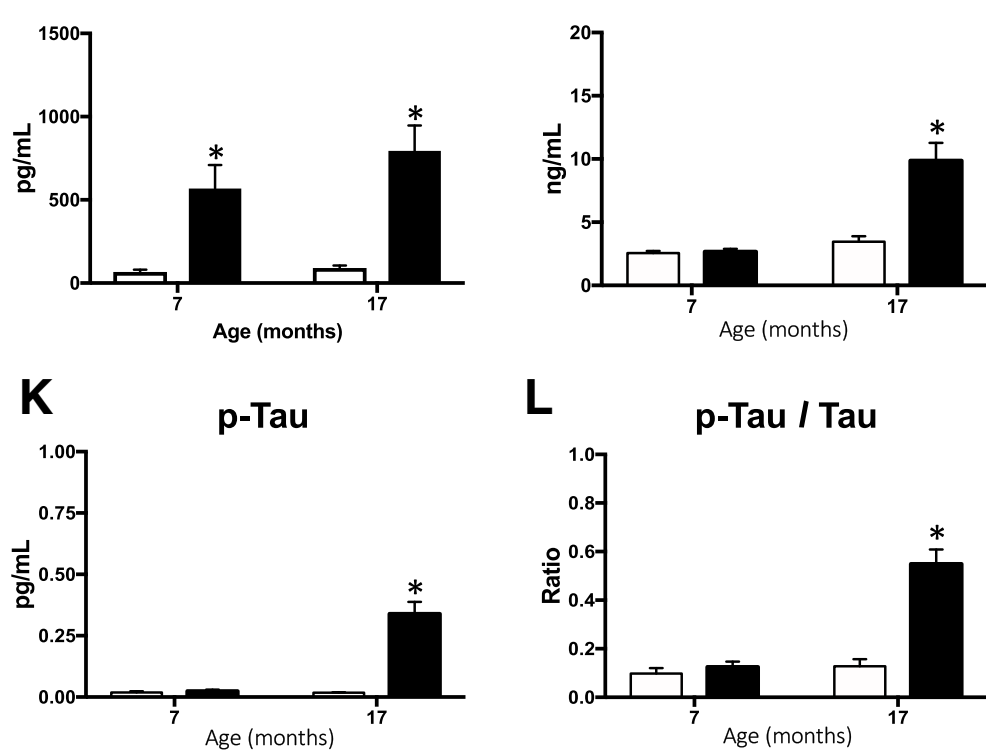

Figure $2 \mathrm{~A} \beta$, kynurenine mediators, TXNIP, oxidative stress, and tau levels in the cerebrum of 7- and 17-month-old female 3xTg-AD and WT mice. A: Tryptophan and TXNIP metabolic pathways in 3xTg-AD mice. B-D: Enzyme-linked immunosorbent assay levels of $A \beta_{40}(\mathbf{B}), A \beta_{42}(\mathbf{C})$, and $A \beta_{42} / A \beta_{40}$ ratio $(\mathbf{D})$ are higher in 3xTg-AD mice and increase with age. E: Interferon (IFN)- $\gamma$ levels are lower in 7-month-old and higher in 17-month-old 3xTg-AD mice than WT mice, and they increase with age. $\mathbf{F}$ and $\mathbf{G}$ : Indoleamine 2,3-dioxygenase (ID0; F) and quinolinic acid (QA; $\mathbf{G})$ levels increase with age and are higher in the 17month-old 3xTg-AD mice. H: TXNIP levels are higher in 7- and 17-month-old 3xTg-AD mice. I: 8-Hydroxy-2'-deoxyguanosine (8-0HdG) levels are increased in the 17-month-old 3xTg-AD mice, indicating higher levels of oxidative damage of DNA by reactive oxygen and nitrogen species. J-L: Levels of tau (J), p-tau $(\mathrm{K})$, and the $\mathrm{p}$-tau/tau ratio $(\mathbf{L})$ are higher in the 17-month-old 3xTg-AD mice. Data are expressed as means \pm SEM. * $P<0.05$ versus WT or as indicated. 8 OHdG, 8-hydroxy-2'-deoxyguanosine; APP, amyloid precursor protein; $A \beta$, amyloid beta; TXNIP, thioredoxin-interacting protein; $p$-tau, phosphorylated tau.

significantly higher in cerebrum from aged mice by comparison to the younger mice $[F(1,11)=139.29, P<0.001]$ (Figure 2E). For both genotypes, the level of IDO was significantly higher in cerebrum from aged mice by comparison to the younger mice $[F(1,17)=61.18$, $P<0.001]$. Although there was no difference between $3 \times$ Tg-AD and WT mice at 7 months of age, the level of IDO was significantly higher in cerebrum from 17-month-old 
3xTg-AD mice by comparison to age-matched WT mice $[F(1,17)=14.50, P<0.005]$ (Figure $2 F$ ). In aged mice, the level of QA in the cerebrum was significantly higher in 3xTg-AD mice compared with the WT controls $[F(1,11)=9.067, P=0.001]$. Cerebrum from older mice had significantly higher levels of QA compared with cerebrum from younger mice $[F(1,11)=18.646, P=0.001]$, and the difference between the young and aged 3xTg-AD mice was greater than the difference between the young and aged WT mice $[F(1,11)=4.96, P<0.05]$ (Figure $2 \mathrm{G}$ ). The level of TXNIP was significantly higher in cerebrum from $3 \times T g-A D$ mice compared with the WT controls $[F(1,13)=38.50, P<0.001]$, but it did not differ between the young and aged mice $[F(1,13)=1.51, P=0.24]$ (Figure $2 \mathrm{H}$ ). Although there was no difference between $3 \times$ Tg-AD and WT mice at 7 months of age, the levels of 8OHdG $[F(1,17)=10.01, P<0.05]$ (Figure 2I), tau $[F(1,17)=58.14, P<0.001]$ (Figure $2 \mathrm{~J}$ ), and p-tau $[F(1,17)=22.10, P<0.001]$ (Figure $2 \mathrm{~K}$ ), and the $\mathrm{p}$-tau/tau ratio $[F(1,17)=18.92, P<0.001]$ (Figure $2 \mathrm{~L}$ ) were all significantly higher in cerebrum from 17 -month-old $3 \times$ Tg$\mathrm{AD}$ mice by comparison to the younger mice and agematched WT mice. The results showed that the cognitive deficits observed in the 7-month-old 3xTg-AD mice are associated with increased $A \beta$ and TXNIP expression in the cerebrum, followed by increased tryptophan metabolism, oxidative DNA damage, and tau phosphorylation at 17 months. Given the bidirectional communication between the nervous and immune systems, this raised the questions of whether changes in tryptophan metabolism and Txnip gene expression are tissue specific and whether altered gene expression profiles in peripheral tissue of $3 \mathrm{xTg}-\mathrm{AD}$ mice are linked to changes in immune responsiveness.

\section{$3 x \operatorname{Tg}-A D-$ Associated Splenomegaly, Monocyte Depletion, and Perturbed Cytokine Production}

In the aging mice, protein levels of key mediators of the KP and TRX pathways were examined in the spleen, which has a pivotal role in modulating immune responses. The spleens from 17-month-old 3xTg-AD mice (Figure 3A) are both longer $[t(11)=4.94, P<0.005]$ (Figure 3B) and heavier $[t(11)=6.20, P<0.005]$ (Figure 3C) than spleens from WT mice. Changes in a specific cellular population can be used as a marker of disease progression. ${ }^{39} \mathrm{CD} 4$ and CD8 flow cytometry was used to quantify each lymphocyte subpopulation to determine whether the enlarged $3 \times \mathrm{Tg}-\mathrm{AD}$ spleens had altered T-cell populations. There was a significant reduction in both CD4 and CD8 cells in the spleens of $3 \times$ Tg-AD mice $[t(4)=9.15, P<0.005$; and $t(4)=5.45$, $P<0.05$, respectively] (Figure 3D). Under a polyclonal immune activation with anti-CD3 and CD28 beads, the enlarged 3xTg-AD spleens produced less tumor necrosis factor and IFN- $\gamma$ relative to their weight than WT spleen $[t(8)=4.06, P<0.005$; and $t(8)=3.85, P<0.005$, respectively] (Figure 3, E and F). In summary, the aged 3xTg-AD mice have splenomegaly but depleted $\mathrm{T}$ lymphocytes, with a coordinated reduction in proinflammatory cytokine production on activation.
A

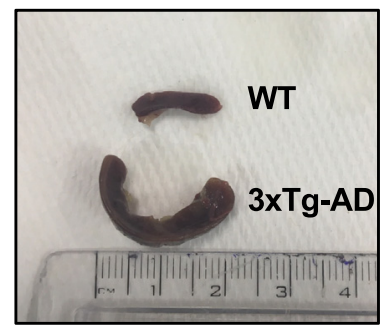

D

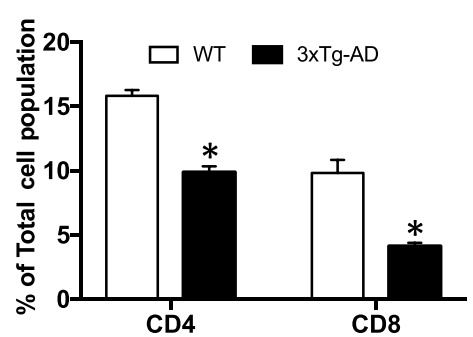

B

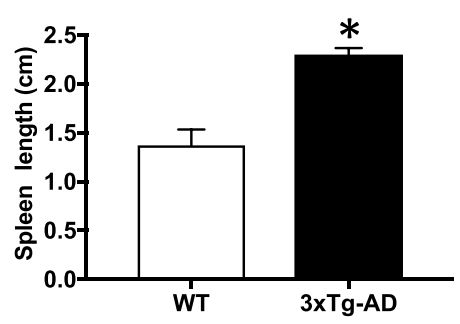

E

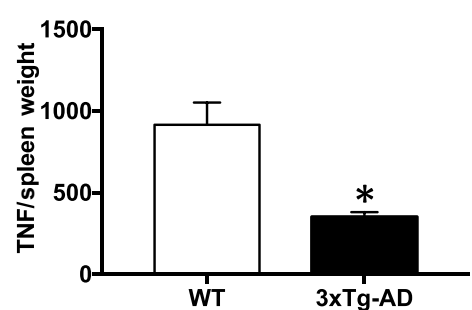

C

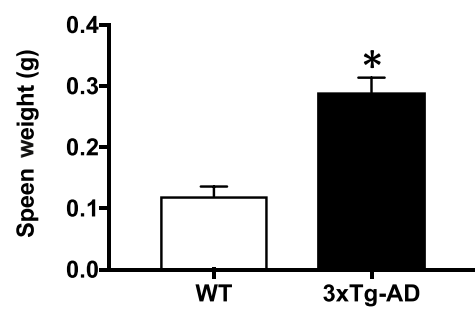

$\mathbf{F}$

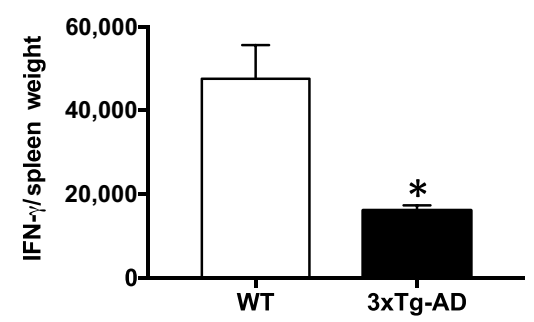

Figure 3 Spleen phenotype and cytokine production in 17-month-old female $3 \times \mathrm{Tg}-\mathrm{AD}$ and WT mice. A-C: The enlarged spleens from $3 \times \mathrm{Tg}-\mathrm{AD}$ mice (A) are longer (B) and heavier (C). D: 3xTg-AD mice spleens have less CD4 and CD8 cells. E and F: $3 \times$ Tg-AD mice spleens produce less tumor necrosis factor (TNF; E) and interferon (IFN) $\gamma(\mathbf{F})$ under the immune challenge in ratio to their weight. Data are expressed as means \pm SEM. ${ }^{\star} P<0.05$ versus WT. CD, cluster of differentiation. 
$3 \times T g-A D-$ Associated Increases of $A \beta, I D 0, Q A, 8-$ OHdG, and ( $p-)$ Tau, but Decrease of TXNIP, in Aged Spleen

The mechanisms that define splenic phenotypic and functional heterogeneity include several molecular pathways, including KP and oxidation-reduction pathways. The levels of key mediators of the KP and TRX pathways - A $\beta_{40}$, $\mathrm{A} \beta_{42}$, IFN- $\gamma$, IDO, QA, TXNIP, 8-OHdG, tau, and $\mathrm{p}-$ tau-were measured in spleens from 17-month-old female
3xTg-AD mice and compared with age- and sex-matched WT control mice without splenomegaly, monocyte depletion, or reduced cytokine production. Levels of $A \beta_{40}$ $[t(4.13)=3.18, P<0.05]$ (Figure $4 \mathrm{~A}$ ) and $\mathrm{A} \beta_{42}$ $[t(4.00)=6.54, P<0.005]$ (Figure $4 \mathrm{~B})$ in the spleen were significantly higher in the $3 \times \mathrm{Tg}-\mathrm{AD}$ mice than the WT mice. Although there was a trend for 3xTg-AD mice to have higher ratios ( $95 \% \mathrm{CI},-0.025$ to 1.366 ), the $\mathrm{A} \beta_{42} / \mathrm{A} \beta_{40}$ ratio did not differ significantly between the $3 \times \mathrm{Tg}-\mathrm{AD}$ and WT mice $[t(4.04)=2.67, P>0.05]$ (Figure 4C). Levels of
A

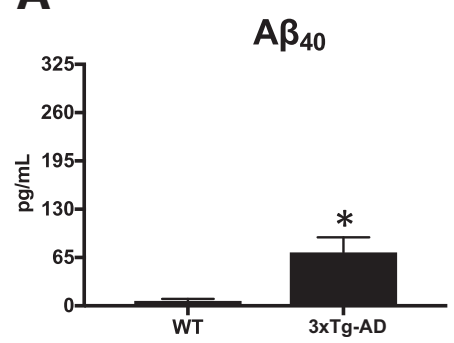

D

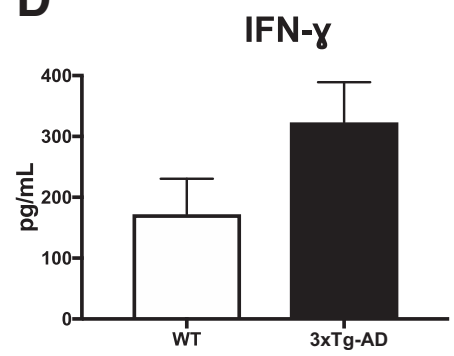

G

TXNIP

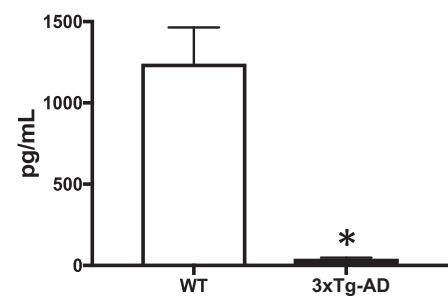

I

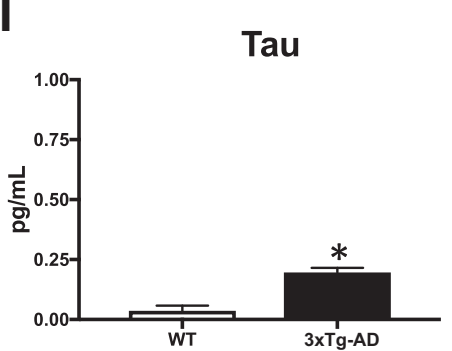

B

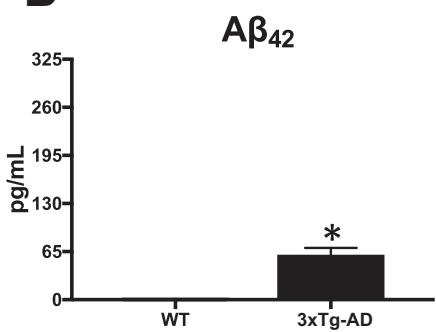

E

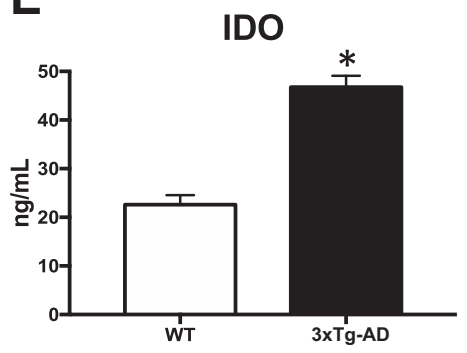

H

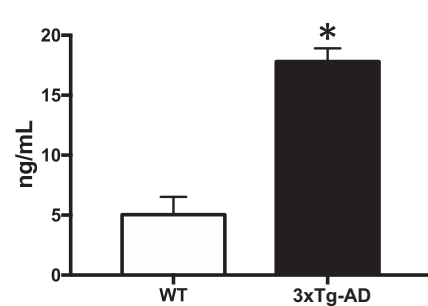

$\mathrm{J}$

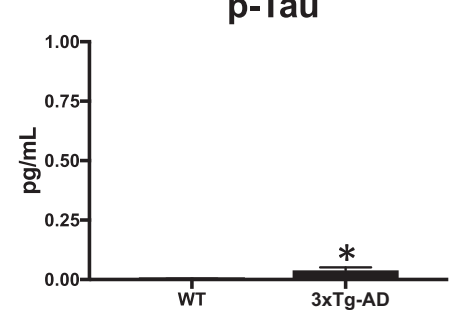

C

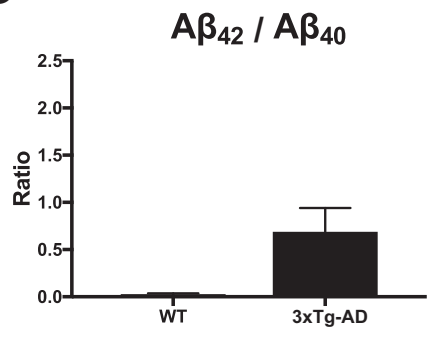

$\mathbf{F}$

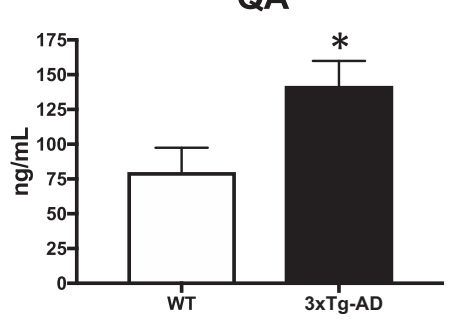

K

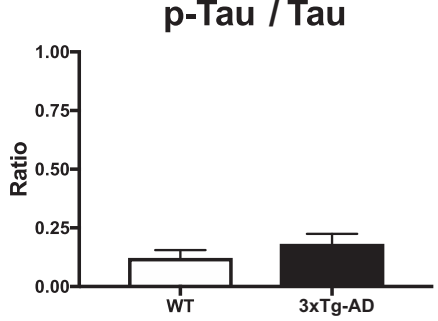

Figure $4 A B$, kynurenine mediators, TXNIP, oxidative stress, and tau levels in the spleen of 17-month-old female 3xTg-AD and WT mice. A and B: Enzymelinked immunosorbent assay levels of $A \beta_{40}(\mathbf{A})$ and $A \beta_{42}(\mathbf{B})$ are higher in $3 \times \mathrm{Tg}-\mathrm{AD}$ mice. $\mathbf{C}$ and $\mathbf{D}$ : The $A \beta_{42} / A \beta_{40}$ ratio (C) and interferon (IFN)- $\gamma$ levels (D) do not differ between 3xTg-AD and WT mice. E-G: Indoleamine 2,3-dioxygenase (ID0; E) and quinolinic acid (QA; F) levels are higher, but TXNIP levels (G) are lower, in 3xTg-AD mice. $\mathbf{H}-\mathbf{J}$ : Levels of 8-hydroxy-2'-deoxyguanosine (8-0HdG; $\mathbf{H})$, tau (I), and p-tau (J) are higher in 3xTg-AD mice. K: The p-tau/tau ratio does not differ between $3 \times \mathrm{Tg}-\mathrm{AD}$ and WT mice. Data are expressed as means \pm SEM. ${ }^{*} P<0.05$ versus WT. A $\beta$, amyloid beta; TXNIP, thioredoxin-interacting protein; p-tau, phosphorylated tau. 
IFN- $\gamma$ were not significantly different between the $3 \times \mathrm{Tg}$ AD and WT mice $[t(7.00)=1.71, P>0.05]$ (Figure 4D). The levels of IDO $[t(8.73)=8.70, P<0.001]$ (Figure 4E) and QA $[t(6.90)=2.48, P<0.05]$ (Figure $4 \mathrm{~F})$ in the spleen were significantly higher in the $3 \times \mathrm{Tg}$-AD mice compared with the WT controls. The level of TXNIP in the spleen was significantly lower in $3 \times \mathrm{Tg}$-AD mice compared with the WT controls $[t(3.01)=-5.39, P<0.05]$ (Figure $4 \mathrm{G}$ ). The level of 8-OHdG in the spleen was significantly higher in the 3xTg-AD mice compared with the WT controls $[t(6.28)=6.92, P<0.001]$ (Figure $4 \mathrm{H}$ ). The levels of tau $[t(6.16)=7.42, P<0.001]$ (Figure $4 \mathrm{I}$ ) and $\mathrm{p}$-tau $[t(6.00)=4.06, P<0.005]$ (Figure $4 \mathrm{~J}$ ) in the spleen were significantly higher in $3 \mathrm{xTg}-\mathrm{AD}$ mice by comparison to the WT mice. Finally, the p-tau/tau ratio was not significantly different between the $3 \times T g-A D$ and WT mice $[t(6.85)=1.74, P>0.05]$ (Figure $4 \mathrm{~K}$ ).

Together, these findings suggest cognitive deficits in $3 \times \mathrm{Tg}-\mathrm{AD}$ mice are associated with a stable increase in levels of $\mathrm{A} \beta_{40} / \mathrm{A} \beta_{42}$ and tau/p-tau accumulation, tryptophan metabolites, and oxidative stress in the cerebrum. At 17 months of age, these cerebral pathologies are accompanied by a coordinated reduction in spleen proinflammatory cytokine (tumor necrosis factor and IFN- $\gamma$ ) production as well as increased $A \beta_{40} / A \beta_{42}$, tau/p-tau, $\mathrm{QA}$, and $8-\mathrm{OHdG}$ accumulation. Interestingly, levels of TXNIP expression were higher in the cerebrum and lower in the enlarged spleens of 3xTg-AD mice compared with WT control mice, suggesting that deficits in visual-spatial learning, oxidative stress, and immune responsivity with aging are associated with changes in tissue-specific Txnip gene regulation. Gene expression is controlled by chromatin structure, which is composed of histone modifications and DNA methylation. ${ }^{40}$ We tested the hypothesis that the $3 \times \mathrm{Tg}$-AD genotype is associated with changes in histone modification and DNA methylation of the Txnip gene promoter and that these changes are associated with altered transcription factor binding, TXNIP expression, cerebral-spleen tryptophan metabolism, and inflammatory cytokine production.

\section{3xTg-AD-Associated Tissue-Specific Variation in Txnip Gene Expression}

Western blot analysis of brain and spleen tissue from 17month-old mice (Figure 5A) confirmed the enzyme-linked immunosorbent assay results (Figures $2 \mathrm{H}$ and $4 \mathrm{G}$ ) that levels of TXNIP are significantly higher in the cerebrum $[t(6)=8.15, P<0.005]$ and significantly lower in the spleen $[t(6)=8.62, P<0.005]$ of the $3 \times$ Tg-AD mice than in WT control mice. The $5^{\prime}$-untranslated region of the Txnip gene promoter region contains a binding site for CTCF (Figure 5C), which can act as a transcriptional activator. ${ }^{41,42}$ Consistent with the levels of TXNIP, the levels of CTCF were significantly higher in the cerebrum $[t(6)=8.15$, $P<0.005]$ and significantly lower in the spleen $[t(6)=8.62, P<0.005]$ of the $3 \times \mathrm{Tg}-\mathrm{AD}$ mice than the WT control mice. Furthermore, Txnip mRNA transcript levels were significantly higher in the cerebrum $[t(6)=5.43$, $P<0.05]$ and significantly lower in the spleen $[t(6)=8.43$, $P<0.05$ ] (Figure 5B) of the $3 \times \mathrm{Tg}-\mathrm{AD}$ mice by comparison to WT control mice.

\section{$3 x \operatorname{Tg}-A D-$ Associated Tissue-Specific Variation in Chromatin Structure}

Gene expression is regulated by chromatin, which gates the accessibility of promoters to transcription factors. ${ }^{43}$ Histone acetylation at the lysine-9 residue of $\mathrm{H} 3$ (H3K9Ac) is a marker of active chromatin, whereas $\mathrm{H} 3 \mathrm{~K} 9$ trimethylation (H3K9me3) is a marker of inactive chromatin. ${ }^{44}$ Acetylation of the histone tails neutralizes the positively charged histones, which disrupts histone binding to negatively charged DNA and promotes transcription factor binding and gene expression. Trimethylation of the histone tails does not destabilize the histone-DNA interaction, which prevents transcription factor binding and promotes gene silencing. The hypothesis that the 3xTg-AD-associated increase in Txnip gene expression in the cerebrum is associated with increased H3K9Ac association with the Txnip gene promoter and increased interaction between CTCF and the promoter sequence was tested. The hypotheses are that the 3xTg-AD-associated decrease in Txnip gene expression in the spleen is associated with increased $\mathrm{H} 3 \mathrm{~K} 9 \mathrm{me} 3$ association with the Txnip gene promoter and decreased interaction between CTCF and the promoter sequence. In $\mathrm{AD}, \mathrm{A} \beta_{42}$ has been proposed to act as an activating transcription factor, ${ }^{45}$ suggesting an association of $A \beta_{42}$ with $A \beta I D$ regions on the Txnip promoter could also influence Txnip gene activity; this was also tested. To test these hypotheses, ChIP analysis was performed, measuring histone acetylation (H3K9Ac) and histone methylation (H3K9me3) within the A $3 \mathrm{ID}$ and CTCF binding regions of the Txnip gene promoter in brain and spleen tissue from 17-month-old 3xTg-AD and WT mice (Figure 5D). There were significantly lower levels of H3K9me3 $[t(4)=8.7083, P<0.05]$ and higher levels of H3K9Ac $[t(4)=7.1153, P<0.05]$ associated with the A $\beta$ ID binding region and significantly lower levels of H3K9me3 $[t(4)=4.6611, P<0.05]$ and higher levels of H3K9Ac $[t(4)=6.9204]$ associated with the CTCF binding region on the Txnip gene promoter in cerebrum from 3xTgAD mice compared with WT control mice. Levels of H3K9me3 $[t(4)=0.7206, P>0.05]$ and H3K9Ac $[t(4)=0.2323, P>0.05]$ associated with the A $\beta$ ID binding regions on the Txnip gene promoter were not significantly different in spleen from $3 \times \mathrm{Tg}-\mathrm{AD}$ and WT control mice (with an overall higher level of $\mathrm{H} 3 \mathrm{~K} 9 \mathrm{me} 3$ compared with H3K9Ac for both genotypes; $P<0.05$ ). However, there were significantly lower levels of H3K9me3 $[t(4)=8.7083$, $P<0.05]$ and H3K9Ac $[t(4)=9.9218, P<0.05]$ associated with the CTCF binding region on the Txnip gene promoter in spleen from $3 \times \mathrm{Tg}-\mathrm{AD}$ mice by comparison to 3xTg-AD mice. 
A

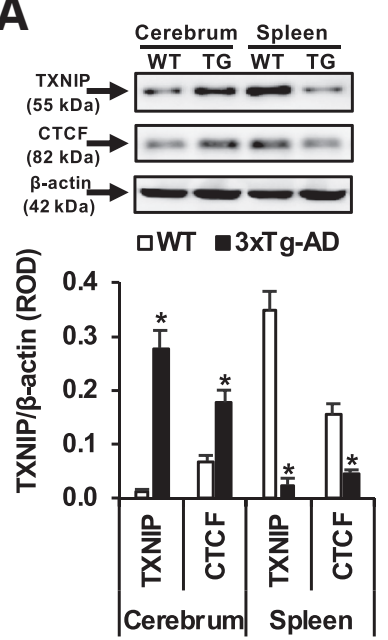

B

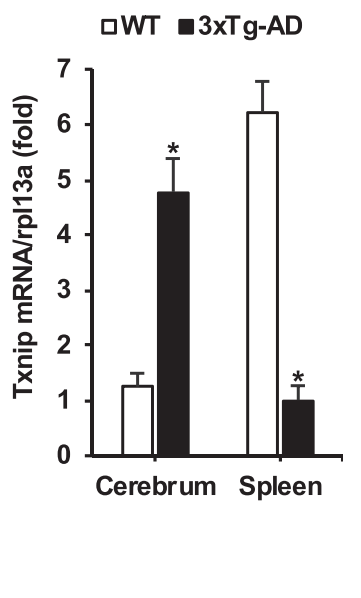

C

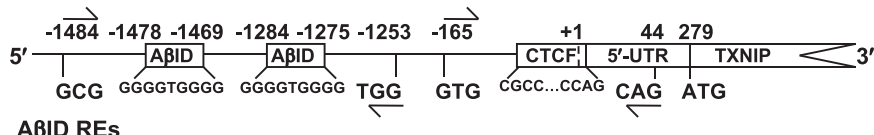

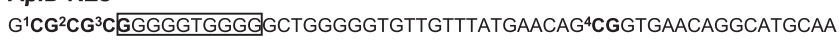
$T^{5} \mathrm{CGCTTTTTACTTCTCCATCTTAATCTCAGGGCTATATCATCTTTATTTTCCTG}{ }^{6} \mathrm{CGCAAGGAA}$ GGAGATAGATAGTCTCCTAATAATTCTGCCCAAATATGGAAGGAGTTTAGGACTCAATGACAA

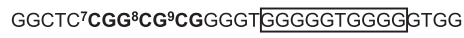

CTCF RE

GTGTCCA ${ }^{1} \mathrm{CG}$ CGCCC $^{3} \mathrm{CGG}^{4} \mathrm{CGGCCT}^{5} \mathrm{CGCTGATTGGTTGGAGGCCTGGTAAACAAGGGCCA}$

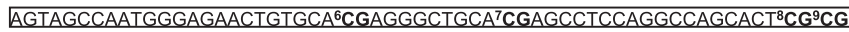
TGGAG ${ }^{10} \mathrm{CGCCAAGCCAGG}^{11} \mathrm{CGGCTATATAAGC}^{12} \mathrm{CGTTTC}^{13} \mathrm{CGGCAGC}^{14} \mathrm{CGCTTGACACTCT}$ CCTCCTCTGGTCT ${ }^{15} \mathrm{CGGGGTTTTCCAGAGTTTCTCCAG}$
D

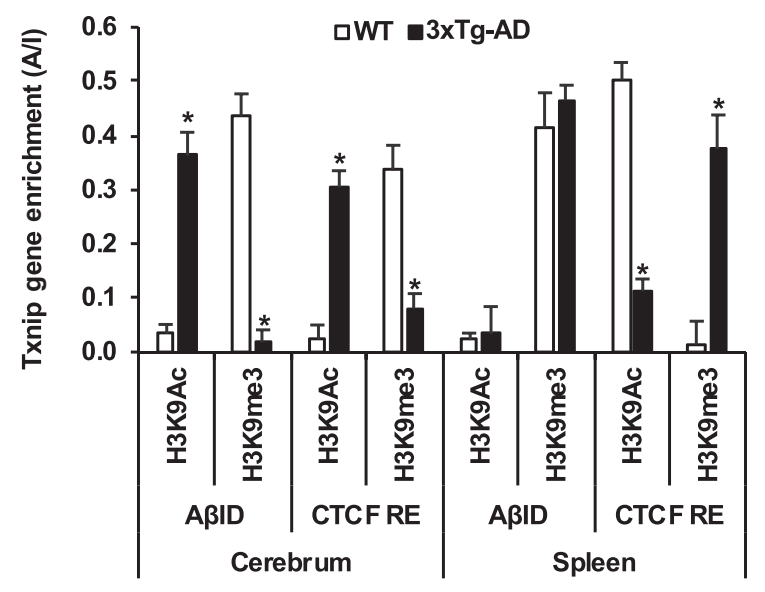

E

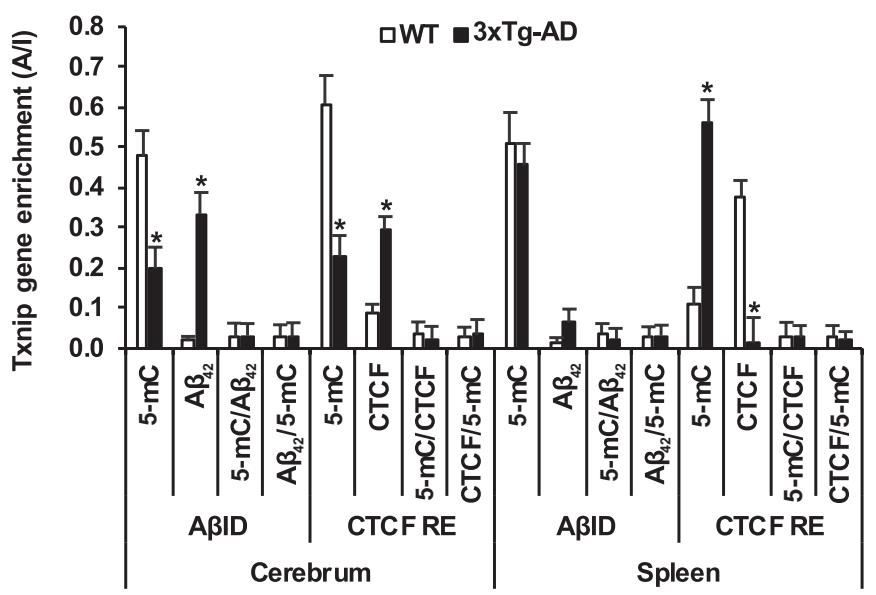

Figure 5 Regulation of Txnip gene expression by histone modification [histone acetylation at the lysine-9 residue of H3 (H3K9Ac) and H3K9 trimethylation (H3K9me3)] and transcription factor [A $\beta_{42}$ and CCCTC-binding factor (CTCF)] association in the cerebrum and spleen of female $3 \times \mathrm{Tg}-\mathrm{AD}$ and WT mice. A and $\mathbf{B}$ : Western TXNIP and CTCF protein levels (A) and real-time quantitative PCR Txnip mRNA transcript levels (B) are higher in cerebrum and lower in spleen of 3xTgAD mice (opposite effect in WT mice). C: Schematic representation of the Txnip gene promoter to show the location of the A $\beta$ interacting domain (A $\beta I D)$ and CTCF response elements (REs; boxed areas), Txnip transcription start site (TSS; +1 ), and primer binding sites. Beneath is shown the two regions of DNA interrogated by pyrosequencing: the location of nine $\mathrm{CpG}$ sites (bold) relative to the primer set flanking the two ABID REs (boxed areas); and the location of $15 \mathrm{CpG}$ sites (bold) relative to the primer set flanking the CTCF RE (boxed areas) and Txnip TSS (underlined). D: Chromatin immunoprecipitation (ChIP)quantitative PCR levels of H3K9Ac association with the Txnip gene promoter A $3 I D$ and CTCF REs are higher in cerebrum and lower in spleen of 3xTg-AD mice (opposite effect with $\mathrm{H} 3 \mathrm{~K} 9 \mathrm{me} 3$ and WT mice tissues). E: Double-ChIP-qPCR levels of DNA methylation and CTCF association with the Txnip gene promoter are lower and higher, respectively, in cerebrum of $3 \times \mathrm{Tg}$-AD mice (opposite effect in spleen and WT mice tissues). A $\beta_{42}$ association is similar to CTCF in the cerebellum but does not bind to the hypermethylated Txnip gene promoter in spleen of $3 \times \mathrm{Tg}$-AD mice. Data are expressed as means \pm SEM. ${ }^{*} P<0.05$ versus WT. 5-mC, 5-methylcytosine; A/I, antibody/input; CTCF, CCCTC-binding factor; H3K9Ac, histone 3 lysine-9 acetylation; H3K9me3, histone 3 lysine-9 trimethylation; RE, response element; ROD, relative optical density; rpl13a; ribosomal protein L13a; TXNIP, thioredoxin-interacting protein; UTR, untranslated region.

\section{3xTg-AD-Associated Tissue-Specific Variation in DNA Methylation and CTCF Binding}

The next question concerned the functional importance of the differences in histone modification. Changes in chromatin activity states are associated with stable changes in DNA methylation of cytosines in cytosine-phosphateguanine $(\mathrm{CpG})$ dinucleotides $(5-\mathrm{mC})$, often associated with stable variations in gene transcription. ${ }^{46}$ Hypomethylation of $\mathrm{CpG}$ dinucleotides of regulatory regions of genes is associated with an active chromatin structure and transcriptional activation, whereas hypermethylation of $\mathrm{CpG}$ dinucleotides of regulatory regions of genes is associated with a condensed chromatin structure and transcriptional repression. $^{47} \mathrm{~A}$ CHIP and $\mathrm{ChIP}-$ re-ChIP analysis was performed with antibodies toward 5-mC and $\mathrm{A} \beta_{42}$ or $\mathrm{CTCF}$ to determine the relationship between DNA methylation and the association of $A \beta_{42}$ and CTCF with the A $\beta$ ID and CTCF 
binding regions on the Txnip gene promoter in the cerebrum and spleen of the 17-month-old 3xTg-AD and WT control mice (Figure 5E). The double ChIP demonstrated that $\mathrm{A} \beta_{42}$ and CTCF did not bind to methylated DNA (evidenced by decreased Txnip gene enrichment in lanes labeled $\mathrm{A} \beta_{42} / 5$ $\mathrm{mC}, \quad 5-\mathrm{mC} / \mathrm{A} \beta_{42}, \quad \mathrm{CTCF} / 5-\mathrm{mC}, \quad$ and $5-\mathrm{mC} / \mathrm{CTCF}$ (Figure 5E). There was also no significant difference between Txnip gene promoter enrichments from the sequential $\mathrm{A} \beta_{42} / 5-\mathrm{mC}$ and 5-mC/A $\beta_{42}$ immunoprecipitation with the $\mathrm{A} \beta \mathrm{ID}$ region and CTCF binding site in spleen and brain tissue from the 3xTg-AD and WT control mice (all $P$ values $>0.05$ ). Levels of DNA methylation on the A $\beta I D$ region of the Txnip gene promoter in the brain were significantly lower in the $3 \times \mathrm{Tg}$-AD mice compared with the WT mice $[t(4)=3.34, P<0.05]$. Levels of $\mathrm{A} \beta_{42}$ association with the A $\beta I D$ region of the Txnip gene promoter in the brain were significantly higher in the $3 \times \mathrm{XTg}-\mathrm{AD}$ mice compared with the WT controls $[t(4)=5.83, P<0.05]$. Similar to the A $\beta$ ID region, levels of DNA methylation on the CTCF binding site on the Txnip gene promoter in the brain were significantly higher in the $3 \times \mathrm{Tg}-\mathrm{AD}$ mice compared with the WT mice $[t(4)=3.78, P<0.05]$. Levels of CTCF association with the CTCF binding site on the Txnip gene promoter in the brain were also significantly higher in the 3xTg-AD mice compared with the WT controls $[t(4)=5.22, P<0.05]$. There were no significant differences in levels of $\mathrm{A} \beta_{42}[t(4)=0.62, P>0.05]$ or 5$\mathrm{mC}[t(4)=1.44, P>0.05]$ association with their respective Txnip gene promoter binding sites in the spleen between $3 \times \mathrm{Tg}-\mathrm{AD}$ and WT control mice. Unlike the brain, levels of DNA methylation on the A $\beta I D$ region of the Txnip gene promoter in the spleen were significantly higher the $3 \times \mathrm{Tg}$ AD mice compared with the WT mice $[t(4)=6.31$, $P<0.05$ ], accompanied by higher CTCF binding in the WT mice $[t(4)=5.94, P<0.05]$. Although CTCF can have multiple functions, including transcriptional activation and repression, ${ }^{48}$ our results suggest that CTCF may activate transcription of the hypomethylated Txnip gene promoter in the cerebrum and spleen of the 17-month-old mice (Figure 5E). This supports our hypothesis that DNA demethylation is required for stable induction of Txnip mRNA transcription, and it corroborates the chromatin activity states and levels of tissue-specific TXNIP expression in cerebrum and spleen from 17-month-old 3xTg-AD and WT control mice.

\section{3xTg-AD-Associated Tissue-Specific Variation in DNA Methylation of the Txnip Gene Promoter}

Two kinds of changes in DNA methylation are known to affect gene expression: regional, non-site-specific DNA methylation around a promoter and site-specific methylation. ${ }^{49}$ To determine whether DNA methylation of specific target sites on the Txnip gene promoter is altered in the $3 \times \mathrm{Tg}-\mathrm{AD}$ mice, differences in the methylation status of individual cytosines within the $\mathrm{CpG}$ dinucleotides of the
Txnip gene promoter of cerebrum and spleen tissue were mapped from 17-month-old 3xTg-AD and WT mice. Bisulfite pyrosequencing was used, with a particular interest in the regions around the A $\beta I D$ and CTCF response elements (Figure 5C). The results showed significant differences in both global and site-specific methylation of the Txnip gene promoter sequence (Figure 5, D and E). The level of DNA methylation on the A $\beta$ ID region of the Txnip gene promoter was highest in the cerebrum of WT mice, followed by the spleens of the 3xTg-AD and WT mice, and lowest in the cerebrum of the $3 \times \mathrm{Tg}-\mathrm{AD}$ mice $[F(1,10)=34.18, P<0.005]$. Consistent with the double ChIP (Figure 5E), the level of DNA methylation on the A $\beta I D$ region of the Txnip gene promoter in the cerebrum was significantly higher in the $3 \times \mathrm{Tg}-\mathrm{AD}$ mice compared with the WT mice $[F(1,10)=29.19, P<0.005]$ (Figure 6A) and significantly higher in the spleen than the cerebrum of $3 \mathrm{xTg}-\mathrm{AD}$ mice $[F(1,10)=11.64, P<0.05]$. Post-hoc analyses revealed that the level of methylation at each of the nine $\mathrm{CpG}$ sites in the $A \beta I D$ region was significantly lower in the cerebrum of $3 \times \mathrm{Tg}-\mathrm{AD}$ mice than in WT control mice (all $P<0.005$ ) (Figure 6B). Furthermore, the level of methylation at $\mathrm{CpG}$ sites $1,3,4$, and 8 (which lie proximal to the two A $\beta$ ID consensus sequences) (Figure 6B) was significantly higher in the spleen of $3 \times \mathrm{Tg}$ $\mathrm{AD}$ mice than the WT mice. The level of DNA methylation on the CTCF binding site of the Txnip gene promoter was highest in the spleens of the 3xTg-AD mice, followed by the cerebrums of the WT and 3xTg-AD mice, and lowest in the spleens of the WT mice $[F(1,10)=82.89, P<0.005]$. Consistent with the double ChIP (Figure 5E), the level of DNA methylation on the CTCF region of the Txnip gene promoter was significantly lower in the cerebrum $[t(10)=2.66, P<0.05]$ (Figure 6C) and significantly higher in the spleen $[t(10)=3.91, P<0.05]$ of $3 \times \mathrm{Tg}-\mathrm{AD}$ mice compared with the WT mice. Post-hoc analyses revealed that the level of methylation at $\mathrm{CpG}$ sites 3 to 5, 7, 8,10 , and 13 to 15 (which lie within the CTCF consensus sequence) (Figure $6 \mathrm{D}$ ) was significantly higher in the cerebrum and spleen of WT mice compared with $3 \times \mathrm{Tg}-\mathrm{AD}$ mice (all $P<0.05$ ) (Figure 6D); other sites did not show a significant difference. Furthermore, the level of methylation at $\mathrm{CpG}$ sites $1,2,5,7$ to 13 , and 15 was significantly higher in the spleen of the $3 \times \mathrm{Tg}$-AD mice compared with WT control mice (all $P<0.05$ ).

\section{Discussion}

Our findings demonstrate that increased TXNIP expression in the cerebrum is associated with increased histone acetylation, transcription factor (A $\beta_{42}$ and $\left.\mathrm{CTCF}\right)$ binding, and Txnip gene promoter hypomethylation, whereas the attenuated TXNIP expression in the spleen is associated with increased histone methylation, reduced CTCF binding, and Txnip gene promoter hypermethylation (Figure 6E). 


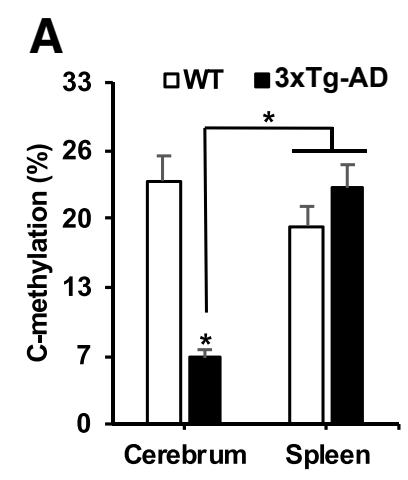

B
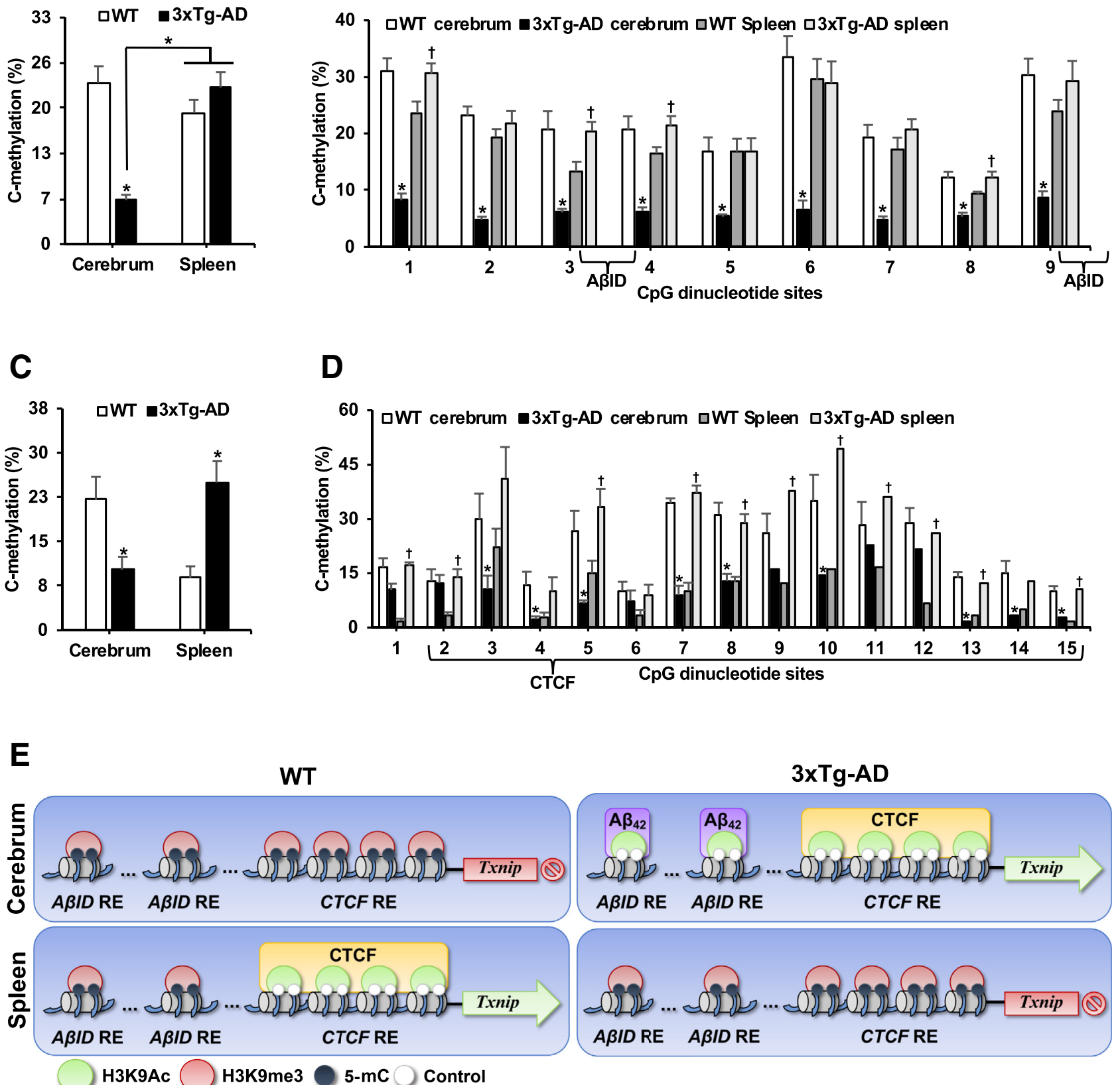

Figure 6 Regulation of Txnip gene expression by DNA methylation of transcription factor (A $\beta_{42}$ and CTCF) binding sites in the cerebrum and spleen of female 3xTg-AD and WT mice. A-D: Bisulfite pyrosequencing confirms overall (A) and site-specific (B) $\mathrm{CpG}$ methylation levels at Txnip gene promoter $\mathrm{A} \beta$ interacting domain (ABID), and CTCF (C and D) response elements (REs) are lower in cerebrum and higher in spleen from 3xTg-AD mice (opposite effect in WT mice). E: Dynamics of histone modification, CpG methylation, and transcription factor binding that control TXNIP gene expression in the cerebrum and spleen of wild-type and 3xTg-AD mice. In wild-type mice: attenuated Txnip gene expression in the cerebrum (top row) is associated with increased histone methylation [lysine-9 residue of $\mathrm{H} 3$ trimethylation (H3K9me3)], A $\beta$ ID and CTCF RE hypermethylation, and reduced transcription factor (A $\beta_{42}$ and CTCF) binding to the Txnip gene promoter. Conversely, enhanced Txnip gene expression in the spleen (bottom row) is associated with increased histone acetylation [histone acetylation at H3K9 (H3K9AC)], CTCF RE hypomethylation, and increased CTCF binding to the Txnip gene promoter (A 3 ID regions have repressive chromatin marks and reduced $A \beta_{42}$ binding association). In the 3xTg-AD mice: enhanced Txnip gene expression in the cerebrum (top row) is associated with increased histone acetylation (H3K9AC), A 3 ID and CTCF RE hypomethylation, and increased transcription factor ( $\mathrm{B}_{42}$ and CTCF) binding to the Txnip gene promoter. Conversely, the attenuated Txnip gene expression in the spleen (bottom row) is associated with increased histone methylation (H3K9me3), A ID and CTCF RE hypermethylation, and reduced transcription factor ( $A \beta_{42}$ and CTCF) binding to the Txnip gene promoter. Herein, increased transcription factor (A $\beta_{42}$ and/or CTCF) binding to the Txnip gene promoter coincides with ABID and/or CTCF RE hypomethylation, reduced histone methylation (H3K9me3), increased histone acetylation (H3K9AC), and enhanced Txnip gene expression. Data are expressed as means \pm SEM. ${ }^{*} P<0.05$ cerebrum versus WT; ${ }^{\dagger} P<0.05$ spleen versus WT. 5-mC, 5-methylcytosine; C-methylation, cytosine-methylation; $\mathrm{CpG}$, cytosine-phosphate-guanine dinucleotides; CTCF, CCCTC-binding factor; Txnip, thioredoxin-interacting protein gene. 
These results, together with the phenotypic analysis of neurobehavioral and splenic function, suggest a causal relationship among epigenomic state, TXNIP expression, cerebral-spleen tryptophan metabolism, inflammatory cytokine production, and cognitive decline; they provide a potential mechanism for Txnip gene regulation in normal and pathologic conditions.

Similar to previous reports, ${ }^{34,50}$ these results show visuospatial learning deficits in young $3 \times \mathrm{Tg}-\mathrm{AD}$ mice, which persist into adulthood. ${ }^{32,50}$ To determine whether visualspatial learning deficits in the Barnes maze at the age of 7 months were associated with $\mathrm{AD}$ neuropathology, $\mathrm{A} \beta_{40}$, $\mathrm{A} \beta_{42}$, IFN- $\gamma$, IDO, QA, TXNIP, 8-OHdG, tau, and p-tau levels were measured in the cerebrums of young and aged $3 \times T g-A D$ and WT mice. The results suggest that overproduction of APP and accumulation of $\mathrm{A} \beta_{42}$ starts before 7 months of age, caused by the Swedish and $P S 1_{M 146 V}$ mutation-associated increase in the $A \beta_{42} / A \beta_{40}$ ratio. Similar to the mice that co-express five familial Alzheimer disease mutations $\left(5 \times \mathrm{xFA}\right.$ mice), ${ }^{29}$ increased $\mathrm{A} \beta_{42}$ promotes TXNIP expression, which binds to and deactivates TRX and decreases oxidative stress. Moreover, $\mathrm{A} \beta_{42}$ accumulation increases KP pathway activity by elevating IDO expression, ${ }^{16}$ which is indicated by an increase in QA. As the mice continue to age, increased oxidative stress further increases $\mathrm{A} \beta_{42}$ accumulation as it increases the activity of the $\beta$ - and $\gamma$-secretase cleavage pathway of APP. ${ }^{51}$ Eventually, A $\beta_{42}$ accumulation triggers an inflammatory immune response by activating pattern recognition receptors, ${ }^{52}$ which are involved in the function of the innate immune system. ${ }^{53}$ Pattern recognition receptor activity increases IFN- $\gamma$, as shown in other diseases, such as tuberculosis ${ }^{54}$ and Porphyromonas gulae infection. ${ }^{55}$ Increased IFN- $\gamma$ further elevates IDO and the breakdown of tryptophan and, therefore, increases the buildup of KP pathway metabolites, such as QA and 3-hydroxykynurenine, which is involved in oxidative stress (indicated by enhanced $8-\mathrm{OHdG}$ levels in older 3xTg-AD mice). Collectively, inflammation, oxidative stress, and neurotoxicity result in the hyperphosphorylation of tau, which is further increased within the neurons because of the P301L mutation in 3xTg-AD mice.

Consistent with previous observations, ${ }^{56,57} 3 \times \mathrm{xTg}-\mathrm{AD}$ mice had larger spleens containing fewer CD4 and CD8 cells than WT mice (Figure 3, A-C). Regulatory T-cell depletion accelerates the onset of cognitive deficits by altering AD-related gene expression and reducing microglia activity against $\mathrm{A} \beta$ deposits. ${ }^{58}$ Indeed, the enhanced $\mathrm{A} \beta$ levels and immune deficits of 5xFAD mice lacking T, B, and natural killer cells can be reversed by bone marrow transfer from immune intact $5 \mathrm{xFAD}$ mice. ${ }^{59}$ Likewise, $\mathrm{CD} 4^{+}$and $\mathrm{CD} 25^{+}$cell transfer improves cognition and reduces plaque deposition in $3 \times \mathrm{Tg}-\mathrm{AD}$ mice. ${ }^{60}$ Herein, we show that when stimulated with $\mathrm{CD} 3 / \mathrm{CD} 28$ beads, spleens harvested from $3 \times \mathrm{Tg}-\mathrm{AD}$ mice secrete lower levels of tumor necrosis factor and IFN- $\gamma$ in ratio to their weight, suggesting differential immune regulation between WT and 3xTg-AD mice. Therein, splenomegaly could be a compensatory mechanism in aged 3xTg-AD mice, as spleens from aged animals are less efficient in initiating an immune response.

To examine whether the splenic deficits in cytokine production at 17 months of age were also associated with AD neuropathology, $A \beta_{40}, A \beta_{42}$, IFN- $\gamma$, IDO, QA, TXNIP, 8 -OHdG, tau, and p-tau levels were measured in the spleen of aged 3xTg-AD and WT mice. To our knowledge, this is the first study to show the presence of $A \beta$ protein, as well as increased IDO and oxidative damage of DNA in the spleens of 3xTg-AD mice. These elevations enhance the validity of the $3 \times \mathrm{Tg}-\mathrm{AD}$ mice as a model for $\mathrm{AD}$, as enriched $\mathrm{A} \beta$ in peripheral tissues in humans carrying the Swedish mutation has been reported ${ }^{61}$ and shown to slow down $A \beta$ clearance in the brain. ${ }^{62}$ Indeed, increased peripheral tissue oxidative damage in mild $\mathrm{AD}$ and cognitive impairment have been linked to apolipoprotein E $\varepsilon 4$ allele carriers. ${ }^{63}$ QA levels are increased in the spleens of $3 \times \mathrm{Tg}-\mathrm{AD}$ mice compared with the WT control mice, which indicates an overactivity of the $\mathrm{KP}$ in the spleen, as occurs in the brain. IDO has been measured in various peripheral tissues, including the lymph nodes, thymus gland, and the spleen. ${ }^{64}$ However, QA is selectively localized to splenic immune cells, ${ }^{65}$ suggesting an immune system origin. Indeed, QA is produced by microglia in the brain rather than neurons or astroglia. ${ }^{21}$ IDO expression is promoted by IFN- $\gamma$ and $A \beta_{42}$. Our results indicate that the elevation of IDO in the $3 \times T g-A D$ spleens is possibly caused by $\mathrm{A} \beta_{42}$ alone because we did not find significantly higher levels of IFN- $\gamma$ in the $3 \times$ Tg-AD mice spleens. The reduced elevation of $I F N-\gamma$ levels may be in response to reduced splenic function in the aged $3 \times \mathrm{Tg}$ $\mathrm{AD}$ mice. Indeed, splenomegaly is associated with lower levels of IFN- $\gamma$ in 12- and 24-month-old 3xTg-AD mice. ${ }^{56}$

These studies offer an opportunity to clearly define the nature of brain-spleen activities and how such effects result in the sustained changes in gene expression and function over the lifespan. Interestingly, TXNIP levels were significantly higher in the spleens of WT mice compared with the $3 x T g-A D$ mice (opposite of what was observed in the brains). The real-time quantitative PCR analysis showed increased Txnip mRNA transcript levels in the spleens of WT mice, suggesting that TXNIP is endogenously produced in the spleens rather than carried in from other tissues. One CTCF binding site and two $A \beta_{42}$ binding regions were found on the mouse Txnip gene promoter, implying that the Txnip gene may be coregulated by $\mathrm{A} \beta_{42}$, which has been shown to act as an activating transcription factor for the APP, $\beta$-secretase, and apolipoprotein E genes. ${ }^{45}$ The potential mechanism for Txnip gene regulation by CTCF and $\mathrm{A} \beta_{42}$ was, therefore, examined. ChIP and double-ChIP assays, measuring chromatin modifications, showed higher acetylation and lower methylation in the brains of the $3 \times \mathrm{Tg}$ $\mathrm{AD}$ mice, both in the $\mathrm{A} \beta \mathrm{ID}$ and CTCF response element regions, suggesting that CNS Txnip gene expression is promoted by both $A \beta_{42}$ and CTCF. On the other hand, the $A \beta I D$ region was heavily methylated in the spleens of both 
3xTg-AD and WT control mice, suggesting $\mathrm{A} \beta_{42}$ alone does not mediate Txnip gene transcription in the spleen. Yet, the CTCF region in the spleens showed higher acetylation and less methylation in the WT mice compared with the $3 \times \mathrm{Tg}$ $\mathrm{AD}$ mice. These results were supported by ChIP assays to study DNA methylation and $A \beta_{42}$ binding as well. Both the $A \beta I D$ and CTCF regions were significantly hypermethylated in the brains of the WT control mice, accompanied by lower $A \beta_{42}$ and CTCF binding, which explains the higher amounts of TXNIP in the brains of the $3 \times T$ Tg-AD mice. In the spleens, however, although the A $\beta I D$ site was hypermethylated in both the 3xTg-AD and the WT mice, the $\mathrm{CTCF}$ region was only hypermethylated in the 3xTg-AD mice, which explains the lower TXNIP levels in the spleens of the 3xTg-AD mice, as well as the much higher levels in the WT spleens.

Higher levels of TXNIP contribute to AD pathogenesis in the brain as TXNIP increases oxidative stress. Interestingly, reduced TXNIP levels in the spleen could accelerate the disease process: in hematopoietic cells, during normal aging, and under increased oxidative stress, TXNIP directly interacts with $\mathrm{p} 53$ to increase its transcriptional activity, which, in turn, decreases oxidative stress. ${ }^{66}$ Along with the bone marrow, the spleen is a major hematopoietic organ in which developing cells reside during maturation. ${ }^{67}$ Increased TXNIP seen in the WT mice may be a part of normal aging, protecting developing blood cells against oxidative damage. Because the levels of TXNIP are much lower in the 3xTg-AD mice than in the WT mice, this may contribute to blood-related abnormalities, such as higher oxygen consumption ${ }^{68}$ or elevated oxidative damage of DNA by reactive oxygen species, as shown by our findings.

To our knowledge, this is the first study to systematically examine anatomical and functional deficits in the spleens of $3 \times T g-A D$ mice and show the transcriptional relationship between $A \beta_{42}$ and TXNIP in the cerebrum and spleen. It is important to keep in mind that the APP, PS1, and tau mutations are the only mutations introduced to these mice, which indicates that oxidative stress and inflammatory deficits are derived by increased $A \beta$ and tau, instead of being independent disease mechanisms. Further studies are required to determine the temporal time point(s) when these functional changes in cerebrum and spleen of the $3 \times T g-A D$ mice occur, and how 3xTg-AD transgenes or their derivatives alter brain-spleen tryptophan metabolism, visualspatial learning, spleen function, and the epigenetic status of the Txnip gene promoter. In addition, the exact causal relationship between DNA methylation and altered histone acetylation and transcription factor $\left(\mathrm{A} \beta_{42}\right.$ and $\left.\mathrm{CTCF}\right)$ binding remains to be defined. DNA methylation represents a stable epigenetic mark; therefore, our findings provide an explanation for the enduring effect of pathologic inflammation on brain function in a common chronic progressive neurodegenerative disorder and suggest TXNIP levels could potentially be a useful predictive or diagnostic biomarker for $\mathrm{A} \beta_{40} / \mathrm{A} \beta_{42}$-targeted $\mathrm{AD}$ therapies.

\section{Acknowledgments}

E.F. and I.C.G.W. conceived and designed the study, collected and analyzed data, and wrote the manuscript; G.R., R.V.W., D.G, A.A.W., and H.J. collected data; A.S. and R.E.B. conceived and designed the study and wrote the manuscript.

\section{References}

1. Jahn H: Memory loss in Alzheimer's disease. Dialogues Clin Neurosci 2013, 15:445-454

2. Armstrong RA: The molecular biology of senile plaques and neuro fibrillary tangles in Alzheimer's disease. Folia Neuropathol 2009, 47: 289-299

3. Mietelska-Porowska A, Wasik U, Goras M, Filipek A, Niewiadomska G: Tau protein modifications and interactions: their role in function and dysfunction. Int J Mol Sci 2014, 15:4671-4713

4. Zhang F, Jiang L: Neuroinflammation in Alzheimer's disease. Neuropsychiatr Dis Treat 2015, 11:243-256

5. Selkoe DJ, Hardy J: The amyloid hypothesis of Alzheimer's disease at 25 years. EMBO Mol Med 2016, 8:595-608

6. Rasouli J, Lekhraj R, Ozbalik M, Lalezari P, Casper D: Brain-spleen inflammatory coupling: a literature review. Einstein J Biol Med 2011 , 27:74-77

7. Bronte V, Pittet MJ: The spleen in local and systemic regulation of immunity. Immunity 2013, 39:806-818

8. Vida G, Pena G, Deitch EA, Ulloa L: alpha7-Cholinergic receptor mediates vagal induction of splenic norepinephrine. J Immunol 2011 , 186:4340-4346

9. Lai KSP, Liu CS, Rau A, Lanctot KL, Kohler CA, Pakosh M, Carvalho AF, Herrmann N: Peripheral inflammatory markers in Alzheimer's disease: a systematic review and meta-analysis of 175 studies. J Neurol Neurosurg Psychiatry 2017, 88:876-882

10. Khan TK, Alkon DL: Peripheral biomarkers of Alzheimer's disease. J Alzheimers Dis 2015, 44:729-744

11. D'Andrea MR, Nagele RG: Targeting the alpha 7 nicotinic acetyl choline receptor to reduce amyloid accumulation in Alzheimer's disease pyramidal neurons. Curr Pharm Des 2006, 12:677-684

12. Rosas-Ballina M, Tracey KJ: Cholinergic control of inflammation. J Intern Med 2009, 265:663-679

13. Lovell MA, Xie C, Gabbita SP, Markesbery WR: Decreased thioredoxin and increased thioredoxin reductase levels in Alzheimer's disease brain. Free Radic Biol Med 2000, 28:418-427

14. Giil LM, Midttun O, Refsum H, Ulvik A, Advani R, Smith AD Ueland PM: Kynurenine pathway metabolites in Alzheimer's disease. J Alzheimers Dis 2017, 60:495-504

15. Chatterjee P, Goozee K, Lim CK, James I, Shen K, Jacobs KR, Sohrabi HR, Shah T, Asih PR, Dave P, ManYan C, Taddei K, Lovejoy DB, Chung R, Guillemin GJ, Martins RN: Alterations in serum kynurenine pathway metabolites in individuals with high neocortical amyloid-beta load: a pilot study. Sci Rep 2018, 8:8008

16. Guillemin GJ, Smythe GA, Veas LA, Takikawa O, Brew BJ: A beta 1-42 induces production of quinolinic acid by human macrophages and microglia. Neuroreport 2003, 14:2311-2315

17. Widner B, Leblhuber F, Walli J, Tilz GP, Demel U, Fuchs D Tryptophan degradation and immune activation in Alzheimer's disease. J Neural Transm (Vienna) 2000, 107:343-353

18. Moffett JR, Namboodiri MA: Tryptophan and the immune response Immunol Cell Biol 2003, 81:247-265

19. Okuda S, Nishiyama N, Saito H, Katsuki H: 3-Hydroxykynurenine an endogenous oxidative stress generator, causes neuronal cell death with apoptotic features and region selectivity. J Neurochem 1998, 70: 299-307 
20. Wu W, Nicolazzo JA, Wen L, Chung R, Stankovic R, Bao SS, Lim CK, Brew BJ, Cullen KM, Guillemin GJ: Expression of tryptophan 2,3-dioxygenase and production of kynurenine pathway metabolites in triple transgenic mice and human Alzheimer's disease brain. PLoS One 2013, 8:e59749

21. Guillemin GJ: Quinolinic acid, the inescapable neurotoxin. FEBS J 2012, 279:1356-1365

22. Rahman A, Ting K, Cullen KM, Braidy N, Brew BJ, Guillemin GJ: The excitotoxin quinolinic acid induces tau phosphorylation in human neurons. PLoS One 2009, 4:e6344

23. Hwang J, Suh HW, Jeon YH, Hwang E, Nguyen LT, Yeom J, Lee SG, Lee C, Kim KJ, Kang BS, Jeong JO, Oh TK, Choi I, Lee JO, Kim MH: The structural basis for the negative regulation of thioredoxin by thioredoxin-interacting protein. Nat Commun 2014, 5:2958

24. Yoshihara E, Masaki S, Matsuo Y, Chen Z, Tian H, Yodoi J: Thioredoxin/Txnip: redoxisome, as a redox switch for the pathogenesis of diseases. Front Immunol 2014, 4:514

25. Akterin S, Cowburn RF, Miranda-Vizuete A, Jimenez A, Bogdanovic N, Winblad B, Cedazo-Minguez A: Involvement of glutaredoxin-1 and thioredoxin-1 in beta-amyloid toxicity and Alzheimer's disease. Cell Death Differ 2006, 13:1454-1465

26. Hokama M, Oka S, Leon J, Ninomiya T, Honda H, Sasaki K, Iwaki T, Ohara T, Sasaki T, LaFerla FM, Kiyohara Y, Nakabeppu Y: Altered expression of diabetes-related genes in Alzheimer's disease brains: the Hisayama study. Cereb Cortex 2014, 24:2476-2488

27. Zhang C, Nestorova G, Rissman RA, Feng J: Detection and quantification of 8-hydroxy-2'-deoxyguanosine in Alzheimer's transgenic mouse urine using capillary electrophoresis. Electrophoresis 2013, 34:2268-2274

28. Valavanidis A, Vlachogianni T, Fiotakis C: 8-Hydroxy-2'-deoxyguanosine (8-OHdG): a critical biomarker of oxidative stress and carcinogenesis. J Environ Sci Health C Environ Carcinog Ecotoxicol Rev 2009, 27:120-139

29. Melone MAB, Dato C, Paladino S, Coppola C, Trebini C, Giordana MT, Perrone L: Verapamil inhibits Ser202/Thr205 phosphorylation of tau by blocking TXNIP/ROS/p38 MAPK pathway. Pharm Res 2018, 35:44

30. Wang CY, Xu Y, Wang X, Guo C, Wang T, Wang ZY: Dl-3-nbutylphthalide inhibits NLRP3 inflammasome and mitigates Alzheimer's-like pathology via Nrf2-TXNIP-TrX axis. Antioxid Redox Signal 2019, 30:1411-1431

31. Oddo S, Caccamo A, Shepherd JD, Murphy MP, Golde TE, Kayed R, Metherate R, Mattson MP, Akbari Y, LaFerla FM: Triple-transgenic model of Alzheimer's disease with plaques and tangles: intracellular Abeta and synaptic dysfunction. Neuron 2003, 39:409-421

32. Stevens LM, Brown RE: Reference and working memory deficits in the 3xTg-AD mouse between 2 and 15-months of age: a crosssectional study. Behav Brain Res 2015, 278:496-505

33. Stover KR, Campbell MA, Van Winssen CM, Brown RE: Analysis of motor function in 6-month-old male and female 3xTg-AD mice. Behav Brain Res 2015, 281:16-23

34. Stover KR, Campbell MA, Van Winssen CM, Brown RE: Early detection of cognitive deficits in the $3 \times \mathrm{Tg}-\mathrm{AD}$ mouse model of Alzheimer's disease. Behav Brain Res 2015, 289:29-38

35. O'Leary TP, Brown RE: Optimization of apparatus design and behavioral measures for the assessment of visuo-spatial learning and memory of mice on the Barnes maze. Learn Mem 2013, 20:85-96

36. Livak KJ, Schmittgen TD: Analysis of relative gene expression data using real-time quantitative PCR and the 2(-Delta Delta C(T)) method. Methods 2001, 25:402-408

37. Coyle KM, Murphy JP, Vidovic D, Vaghar-Kashani A, Dean CA, Sultan M, Clements D, Wallace M, Thomas ML, Hundert A, Giacomantonio CA, Helyer L, Gujar SA, Lee PW, Weaver IC, Marcato P: Breast cancer subtype dictates DNA methylation and ALDH1A3-mediated expression of tumor suppressor RARRES1. Oncotarget 2016, 7:44096-44112

38. Tost J, Gut IG: Analysis of gene-specific DNA methylation patterns by pyrosequencing technology. Methods Mol Biol 2007, 373:89-102
39. Miller JA, Woltjer RL, Goodenbour JM, Horvath S, Geschwind DH: Genes and pathways underlying regional and cell type changes in Alzheimer's disease. Genome Med 2013, 5:48

40. Weaver IC, Korgan AC, Lee K, Wheeler RV, Hundert AS, Goguen D: Stress and the emerging roles of chromatin remodeling in signal integration and stable transmission of reversible phenotypes. Front Behav Neurosci 2017, 11:41

41. Filippova GN, Fagerlie S, Klenova EM, Myers C, Dehner Y, Goodwin G, Neiman PE, Collins SJ, Lobanenkov VV: An exceptionally conserved transcriptional repressor, $\mathrm{CTCF}$, employs different combinations of zinc fingers to bind diverged promoter sequences of avian and mammalian c-myc oncogenes. Mol Cell Biol 1996, 16: $2802-2813$

42. Klenova EM, Nicolas RH, Paterson HF, Carne AF, Heath CM, Goodwin GH, Neiman PE, Lobanenkov VV: CTCF, a conserved nuclear factor required for optimal transcriptional activity of the chicken c-myc gene, is an 11-Zn-finger protein differentially expressed in multiple forms. Mol Cell Biol 1993, 13:7612-7624

43. Kadonaga JT: Eukaryotic transcription: an interlaced network of transcription factors and chromatin-modifying machines. Cell 1998, 92:307-313

44. Vermeulen M, Eberl HC, Matarese F, Marks H, Denissov S, Butter F, Lee KK, Olsen JV, Hyman AA, Stunnenberg HG, Mann M: Quantitative interaction proteomics and genome-wide profiling of epigenetic histone marks and their readers. Cell 2010, 142:967-980

45. Maloney B, Lahiri DK: The Alzheimer's amyloid beta-peptide (Abeta) binds a specific DNA Abeta-interacting domain (AbetaID) in the APP, BACE1, and APOE promoters in a sequence-specific manner: characterizing a new regulatory motif. Gene 2011, 488: $1-12$

46. D’Alessio AC, Weaver IC, Szyf M: Acetylation-induced transcription is required for active DNA demethylation in methylation-silenced genes. Mol Cell Biol 2007, 27:7462-7474

47. Razin $\mathrm{A}: \mathrm{CpG}$ methylation, chromatin structure and gene silencing: a three-way connection. EMBO J 1998, 17:4905-4908

48. Holwerda SJ, de Laat W: CTCF: the protein, the binding partners, the binding sites and their chromatin loops. Philos Trans R Soc Lond B Biol Sci 2013, 368:20120369

49. Keshet I, Yisraeli J, Cedar H: Effect of regional DNA methylation on gene expression. Proc Natl Acad Sci U S A 1985, 82:2560-2564

50. Attar A, Liu T, Chan WT, Hayes J, Nejad M, Lei K, Bitan G: A shortened Barnes maze protocol reveals memory deficits at 4-months of age in the triple-transgenic mouse model of Alzheimer's disease. PLoS One 2013, 8:e80355

51. Tabaton M, Tamagno E: The molecular link between beta- and gamma-secretase activity on the amyloid beta precursor protein. Cell Mol Life Sci 2007, 64:2211-2218

52. Salminen A, Ojala J, Kauppinen A, Kaarniranta K, Suuronen T: Inflammation in Alzheimer's disease: amyloid-beta oligomers trigger innate immunity defence via pattern recognition receptors. Prog Neurobiol 2009, 87:181-194

53. Kigerl KA, de Rivero Vaccari JP, Dietrich WD, Popovich PG, Keane RW: Pattern recognition receptors and central nervous system repair. Exp Neurol 2014, 258:5-16

54. Hossain MM, Norazmi MN: Pattern recognition receptors and cytokines in Mycobacterium tuberculosis infection: the double-edged sword? Biomed Res Int 2013, 2013:179174

55. Holden JA, O'Brien-Simpson NM, Lenzo JC, Orth RKH, Mansell A, Reynolds EC: Porphyromonas gulae activates unprimed and gamma interferon-primed macrophages via the pattern recognition receptors toll-like receptor 2 (TLR2), TLR4, and NOD2. Infect Immun 2017, 85. e00282-17

56. Yang SH, Kim J, Lee MJ, Kim Y: Abnormalities of plasma cytokines and spleen in senile APP/PS1/tau transgenic mouse model. Sci Rep 2015, 5:15703

57. Marchese M, Cowan D, Head E, Ma D, Karimi K, Ashthorpe V, Kapadia M, Zhao H, Davis P, Sakic B: Autoimmune manifestations 
in the 3xTg-AD model of Alzheimer's disease. J Alzheimers Dis 2014, 39:191-210

58. Dansokho C, Ait Ahmed D, Aid S, Toly-Ndour C, Chaigneau T, Calle V, Cagnard N, Holzenberger M, Piaggio E, Aucouturier P, Dorothee G: Regulatory $\mathrm{T}$ cells delay disease progression in Alzheimer-like pathology. Brain 2016, 139:1237-1251

59. Marsh SE, Abud EM, Lakatos A, Karimzadeh A, Yeung ST, Davtyan H, Fote GM, Lau L, Weinger JG, Lane TE, Inlay MA, Poon WW, Blurton-Jones M: The adaptive immune system restrains Alzheimer's disease pathogenesis by modulating microglial function. Proc Natl Acad Sci U S A 2016, 113:E1316-E1325

60. Baek H, Ye M, Kang GH, Lee C, Lee G, Choi DB, Jung J, Kim H, Lee S, Kim JS, Lee HJ, Shim I, Lee JH, Bae H: Neuroprotective effects of $\mathrm{CD} 4+\mathrm{CD} 25+$ Foxp3 + regulatory $\mathrm{T}$ cells in a $3 \mathrm{xTg}-\mathrm{AD}$ Alzheimer's disease model. Oncotarget 2016, 7:69347-69357

61. Citron M, Vigo-Pelfrey C, Teplow DB, Miller C, Schenk D, Johnston J, Winblad B, Venizelos N, Lannfelt L, Selkoe DJ: Excessive production of amyloid beta-protein by peripheral cells of symptomatic and presymptomatic patients carrying the Swedish familial Alzheimer disease mutation. Proc Natl Acad Sci U S A 1994, 91:11993-11997

62. Marques MA, Kulstad JJ, Savard CE, Green PS, Lee SP, Craft S, Watson GS, Cook DG: Peripheral amyloid-beta levels regulate amyloid-beta clearance from the central nervous system. J Alzheimers Dis 2009, 16:325-329

63. Baldeiras I, Santana I, Proenca MT, Garrucho MH, Pascoal R, Rodrigues A, Duro D, Oliveira CR: Peripheral oxidative damage in mild cognitive impairment and mild Alzheimer's disease. J Alzheimers Dis 2008, 15:117-128

64. Dai X, Zhu BT: Indoleamine 2,3-dioxygenase tissue distribution and cellular localization in mice: implications for its biological functions. J Histochem Cytochem 2010, 58:17-28

65. Moffett JR, Espey MG, Gaudet SJ, Namboodiri MA: Antibodies to quinolinic acid reveal localization in select immune cells rather than neurons or astroglia. Brain Res 1993, 623:337-340

66. Jung H, Kim MJ, Kim DO, Kim WS, Yoon SJ, Park YJ, Yoon SR, Kim TD, Suh HW, Yun S, Min JK, Lee HG, Lee YH, Na HJ, Lee DC, Kim HC, Choi I: TXNIP maintains the hematopoietic cell pool by switching the function of p53 under oxidative stress. Cell Metab 2013, 18:75-85

67. Morita Y, Iseki A, Okamura S, Suzuki S, Nakauchi H, Ema H: Functional characterization of hematopoietic stem cells in the spleen. Exp Hematol 2011, 39:351-359.e3

68. Knight EM, Verkhratsky A, Luckman SM, Allan SM, Lawrence CB: Hypermetabolism in a triple-transgenic mouse model of Alzheimer's disease. Neurobiol Aging 2012, 33:187-193 